\title{
Does Lumpy Investment Matter for Business Cycles?*
}

\author{
Jianjun Miao ${ }^{\dagger} \quad$ Pengfei Wang ${ }^{\ddagger}$
}

January 8, 2010

\begin{abstract}
We present an analytically tractable general equilibrium business cycle model that features micro-level investment lumpiness. We prove an exact irrelevance proposition which provides sufficient conditions on preferences, technology, and the fixed cost distribution such that any positive upper support of the fixed cost distribution yields identical equilibrium dynamics of the aggregate quantities normalized by their deterministic steady state values. We also give two conditions for the fixed cost distribution, under which lumpy investment can be important to a first-order approximation: (i) The steady-state elasticity of the adjustment rate is large so that the extensive margin effect is large. (ii) More mass is on low fixed costs so that the general equilibrium price feedback effect is small.
\end{abstract}

JEL Classification: E22, E32

Keywords: generalized (S,s) rule, lumpy investment, general equilibrium, business cycles, marginal Q, exact irrelevance proposition

\footnotetext{
${ }^{*}$ We thank Fernando Alvarez, Simon Gilchrist, Bob King, and Yi Wen for helpful comments.

${ }^{\dagger}$ Department of Economics, Boston University, 270 Bay State Road, Boston, MA 02215. Tel.: 617-353-6675. Email: miaoj@bu.edu. Homepage: http://people.bu.edu/miaoj.

${ }^{\ddagger}$ Department of Economics, Hong Kong University of Science and Technology, Clear Water Bay, Hong Kong. Tel: (+852) 2358 7612. Email: pfwang@ust.hk
} 


\section{Introduction}

In this paper, we present an analytically tractable general equilibrium business cycle model that incorporates micro-level convex and nonconvex adjustment costs. Recent empirical studies have documented that nonconvexities of microeconomic capital adjustment are widespread phenomena. Examining a 17-year sample of large, continuing US manufacturing plants, Doms and Dunne (1998) find that typically more than half of a plant's cumulative investment occurs in a single episode. In addition, they find that long periods of relatively small changes are interrupted by investment spikes. Using the Longitudinal Research Database, Cooper and Haltiwanger (2006) find that about 8 percent of observations entail an investment rate near zero. These observations of inaction are complemented by periods of rather intensive adjustment of the capital stock. Cooper and Haltiwanger (2006) also estimate structural parameters of a rich specification of convex and nonconvex adjustment costs.

Given the above evidence, an important question is whether micro-level nonconvexities matter for aggregate macroeconomic dynamics. ${ }^{1}$ This question is under significant debate in the literature. In a seminal study, Thomas (2002) challenges the previous partial equilibrium analyses (e.g., Caballero et al. (1995), Cooper et al. (1999), and Caballero and Engel (1999)) by providing a general equilibrium model with lumpy investment. ${ }^{2}$ She applies the Dotsey, King, and Wolman (1999) method and shows quantitatively that lumpy investment is irrelevant for business cycles. Subsequently, Khan and Thomas (2003, 2008) build more general models and use a different numerical method (Krusell and Smith (1998)) to solve the models. ${ }^{3}$ They still obtain a similar finding. Their key insight is that the general equilibrium price feedback effect offsets changes in aggregate investment demand. ${ }^{4}$ However, some researchers remain unconvinced by the Khan-Thomas finding. Bachmann et al. (2008) and Gourio and Kashyap (2007) argue that both fixed adjustment costs and general equilibrium price movements are important for business cycle analysis. The relative importance of these two effects is sensitive to

\footnotetext{
${ }^{1}$ Embedding a partial equilibrium model similar to Abel and Eberly (1998) in a continuous-time general equilibrium framework, Miao (2008) studies the effect of corporate tax policy on long-run equilibrium in the presence of fixed costs and irreversibility.

${ }^{2}$ Veracierto (2002) embeds the partial equilibrium costly irreversibility model of Abel and Eberly (1996) in a general equilibrium business cycles model. Wang and Wen (2009) present a general equilibrium model with irreversible investment to study aggregate and firm-level volatility.

${ }^{3}$ Miao (2006) proves the existence of sequential competitive equilibrium for the Krusell-Smith-style incomplete markets economy with heterogeneous agents. However, it is an open question whether or not the Krusell-Smithtype recursive equilibrium exists. See Heathcote et al. (2009) for a survey of heterogeneous agents models.

${ }^{4}$ House (2008) finds an approximate irrelevance result numerically in a different setup. In his model, the source of the irrelevance result is not the general equilibrium price movements, but is the nearly infinite intertemporal substitution for the timing of investment resulting from long-lived capital.
} 
calibration. Using the Dotsey et al. (1999) method as in Thomas (2002), Gourio and Kashyap (2007) calibrate a larger size of fixed adjustment costs, and argue that for the extensive margin effect to be large, the fixed cost distribution must be compressed in the sense that many firms face roughly the same sized fixed costs.

One reason causing the debate is due to the complexity of the general equilibrium models with heterogeneous firms in this literature. Researchers have to apply complicated numerical methods to solve these models. ${ }^{5}$ There is no general theoretical result for comparison. Without a theoretical result under explicitly stated assumptions, one may doubt the accuracy and generality of numerical solutions. To the best of our knowledge, there is no accuracy test of the Dotsey, King, and Wolman (1999) method applied in the literature of equilibrium models with lumpy investment. In addition, den Haan (2010b) points out that the accuracy test of the Krusell-Smith method based on the $R^{2}$ and the standard error is inadequate and has flaws. There is also no comparison of numerical solutions obtained from these two methods in the lumpy investment literature. Thus, it is important to develop a reference model that can deliver an explicit characterization of equilibrium. This characterization can be used not only for establishing theoretical results, but also for obtaining accurate and efficient numerical solutions.

In the present paper, we propose such an analytically tractable general equilibrium model to understand the aggregate implications of various forms of adjustment costs. Our model features both convex and nonconvex adjustment costs. Firms face aggregate labor-augmenting technology shocks and investment-specific technology shocks. ${ }^{6}$ In addition, firms face idiosyncratic fixed cost shocks, resulting in a generalized (S,s) investment rule as in Caballero and Engel (1999). Our model is similar to the Khan and Thomas (2003) model with two main differences. First, we assume that the firm-level production function has constant returns to scale rather than decreasing returns to scale. This assumption makes the aggregate production function have constant returns to scale, consistent with the real business cycle (RBC) literature. Second, we assume that a firm's fixed costs are proportional to its existing capital stock rather than labor costs. These two assumptions allow us to exploit the homogeneity property of firm value to derive a closed-form solution for the generalized (S,s) investment rule. They also allow us to derive exact aggregation so that we can represent aggregate equilibrium dynamics by a system

\footnotetext{
${ }^{5}$ Recently, researchers have developed some new numerical methods to solve models with heterogeneous agents. These methods are summarized in the January 2010 issue of the Journal of Economic Dynamics and Control. den Haan (2010a) provides a comparison of these methods when applied to the Krusell and Smith (1998) model. It is interesting to see how these methods are applied to solve the lumpy investment model.

${ }^{6}$ Greenwood et al. (2000) and Fisher (2006) emphasize that investment-specific technology shocks are important for business cycles.
} 
of nonlinear difference equations as in the $\mathrm{RBC}$ literature. In particular, the distribution of capital matters only to the extent of its mean. We then prove that the competitive equilibrium is constrained efficient in the sense that if a social planner decides allocations taken firm-level convex and nonconvex adjustment costs as given, then the optimal allocations are the same as those in a competitive equilibrium. This result also implies that a recursive equilibrium exists and unique, which provides the theoretic foundation for a recursive method to solve the model numerically.

The benefit of our modelling is that we do not need to use a complicated numerical method (e.g., Krusell and Smith (1998)) to approximate the distribution of capital. Because we characterize equilibrium dynamics by a system of nonlinear difference equations, we can use a standard numerical method to obtain accurate solutions. In particular, we apply the secondorder approximation method (Schmitt-Grohe and Uribe (2004)), which proves quite efficient and accurate for analyzing business cycles (see Aruoba et al. (2006)). In addition, we can also use the standard log-linear approximation method to flesh out intuition transparently by pencil and paper. Both methods can be easily implemented numerically using the publicly available package - Dynare. The cost of our modelling is that our model cannot address distributional asymmetry and nonlinearity emphasized by Caballero et al. (1995). Nevertheless, our model is still rich enough for us to analyze business cycles with the essential feature of micro-level lumpiness, but also is tractable enough for us to analyze theoretically the effects of intensive margin, extensive margin, and general equilibrium price movements, which are the most important elements emphasized in the literature.

We derive the following main results. First, we prove an exact irrelevance proposition: If the production function is Cobb-Douglas, preferences are represented by a time-additive expected utility function consistent with balanced-growth path, and the idiosyncratic fixed cost shocks are drawn independently and identically from a power function distribution, then any positive upper support of the fixed cost distribution yields identical equilibrium dynamics of the aggregate quantities normalized by their deterministic steady-state values.

Second, we derive conditions under which lumpy investment is important for aggregate dynamics to a first order approximation. Essentially, we need the extensive margin effect to be large and the general equilibrium price feedback effect to be small. We show that the extensive margin effect is determined by the steady-state elasticity of the adjustment rate with respect to the investment trigger. The larger is this elasticity, the larger is the extensive margin effect. The general equilibrium price feedback effect is determined by preferences and the steady-state ratio of the option value of waiting to the price of capital. When the elasticity of intertemporal 
substitution is large, the interest rate feedback effect is small. When the fixed cost distribution is more right skewed (i.e. more firms have small fixed costs), the option value of waiting is larger, leading to a weaker general equilibrium wage feedback effect.

Third, we show numerically that introducing fixed costs to a model with convex adjustment costs raises business cycle volatility, but reduces persistence of output, consumption, investment, and hours. In addition, when lumpy investment becomes more important, it brings business cycle moments closer to those in the standard frictionless RBC model.

Our theoretical results may reconcile some of the debate and some of the numerical findings in the literature. For example, Khan and Thomas $(2003,2008)$ find that when they increase the maximal fixed cost by 10 folds, the equilibrium dynamics nearly have no change. This is due to the fact that they assume a uniform distribution of fixed costs and a nearly constantreturns-to-scale production function (their calibrated value of returns to scale is 0.905 or 0.896 ). For the maximal size of fixed costs to matter, we need the production function to have high curvature as shown numerically by Gourio and Kashyap (2007) and Bachmann et al. (2008). Gourio and Kashyap (2007) also argue that the fixed cost distribution must be compressed. We show that this feature of the distribution is not essential. What is essential is that the fixed cost distribution must be right skewed and must have a high steady-state elasticity of the adjustment rate.

We emphasize that the size of total fixed costs is not essential for the lumpy investment to be important. Gourio and Kashyap (2007) argue that Khan and Thomas calibrated fixed costs are too small and that raising the size of total fixed costs will make lumpy investment more important. By contrast, we use numerical examples to show that even the size of fixed costs is smaller, lumpy investment can be more important for the reason discussed before.

The remainder of the paper proceeds as follows. Section 2 presents the model. Section 3 analyzes equilibrium properties. Section 4 provides numerical results. Section 5 concludes. An appendix contains all proofs.

\section{The Model}

We consider an infinite horizon economy. Time is discrete and indexed by $t=0,1,2, \ldots$. There is a continuum of heterogeneous production units, indexed by $j$ and distributed uniformly over $[0,1]$. We identify a production unit with a firm or a plant. There is a continuum of identical households, who trade all firms' shares. Each firm is subject to aggregate labor-augmenting productivity shocks and investment-specific technology shocks. In addition, each firm is subject 
to idiosyncratic shocks to fixed adjustment costs of investments. To focus on the implications of fixed costs for business cycles, we abstract from long-run growth. It is straightforward to incorporate growth because our model assumptions are consistent with balanced growth.

\section{$2.1 \quad$ Firms}

All firms have an identical production technology that combines labor and capital to produce output. Specifically, if firm $j$ owns capital $K_{t}^{j}$ and hires labor $N_{t}^{j}$, it produces output $Y_{t}^{j}$ according to the production function:

$$
Y_{t}^{j}=F\left(K_{t}^{j}, A_{t} N_{t}^{j}\right)
$$

where $A_{t}$ represents aggregate labor-augmenting technology shocks and follows a Markov process given by:

$$
\ln A_{t+1}=\rho_{A} \ln A_{t}+\sqrt{1-\rho_{A}^{2}} \sigma_{A} e_{A, t+1} .
$$

Here, $\rho_{A} \in(0,1), \sigma_{A}>0$ and $e_{A, t}$ is an identically and independently distributed (iid) standard normal random variable. Assume that $F$ is strictly increasing, strictly concave, continuously differentiable, and satisfies the usual Inada conditions. In addition, it has constant returns to scale.

Each firm $j$ may make investment $I_{t}^{j}$ to increase its existing capital stock $K_{t}^{j}$. Investment incurs both nonconvex and convex adjustment costs. As in Uzawa (1969), Baxter and Crucini (1993), and Jermann (1998), capital accumulation follows the law of motion:

$$
K_{t+1}^{j}=(1-\delta) K_{t}^{j}+K_{t}^{j} \Phi\left(\frac{I_{t}^{j}}{K_{t}^{j}}\right), K_{0}^{j} \text { given, }
$$

where $\delta$ is the depreciation rate and $\Phi$ represents convex adjustment costs. To facilitate analytical solutions, we follow Jermann (1998) and specify the adjustment cost function as:

$$
\Phi(x)=\frac{\psi}{1-\theta} x^{1-\theta}+\varsigma,
$$

where $\psi>0$ and $\theta \in(0,1)$. Nonconvex adjustment costs are fixed costs that must be paid if and only if the firm chooses to invest. As in Cooper and Haltiwanger (2006), we measure these costs as a fraction of the firm's capital stock. ${ }^{7}$ That is, if firm $j$ makes new investment, then it pays fixed costs $\xi_{t}^{j} K_{t}^{j}$, which is independent of the amount of investment. As will be clear later, this

\footnotetext{
${ }^{7}$ There are several ways to model fixed adjustment costs in the literature. Fixed costs may be proportional to the demand shock (Abel and Eberly (1998)), profits (Caballero and Engel (1999) and Cooper and Haltiwanger (2006)), or labor costs (Thomas (2002) and Khan and Thomas (2003, 2008)).
} 
modelling of fixed costs is important to ensure that firm value is linearly homogenous. Following Caballero and Engel (1999), we assume that $\xi_{t}^{j}$ is identically and independently drawn from a distribution with density $\phi$ over $\left[0, \xi_{\max }\right]$ across firms and across time. These idiosyncratic costs cause firm heterogeneity.

Each firm $j$ pays dividends to households who are shareholders of the firm. Dividends are given by:

$$
D_{t}^{j}=Y_{t}^{j}-w_{t} N_{t}^{j}-\frac{I_{t}^{j}}{z_{t}}-\xi_{t}^{j} K_{t}^{j} \mathbf{1}_{I_{t}^{j} \neq 0}
$$

where $w_{t}$ is the wage rate, and $z_{t}$ represents aggregate investment-specific technology shocks. Here $\mathbf{1}_{I_{t}^{j} \neq 0}$ is an indicator function taking value 1 if $I_{t}^{j} \neq 0$, and value 0 , otherwise. Assume $z_{t}$ follows a Markov process given by:

$$
\ln z_{t+1}=\rho_{z} \ln z_{t}+\sqrt{1-\rho_{z}^{2}} \sigma_{z} e_{z, t+1},
$$

where $\rho_{z} \in(0,1), \sigma_{z}>0$, and $e_{z, t}$ is an iid standard normal random variable. All random variables $A_{t}, z_{t}$ and $\xi_{t}^{j}$ are mutually independent.

Firm $j$ 's objective is to maximize cum-dividends market value of equity $P_{t}^{j}$ :

$$
\max P_{t}^{j} \equiv E_{t}\left[\sum_{s=0}^{\infty} \beta^{s} \frac{\Lambda_{t+s}}{\Lambda_{t}} D_{t+s}^{j}\right],
$$

subject to (2) and (4). Here, $\beta^{s} \Lambda_{t+s} / \Lambda_{t}$ is the stochastic discount factor between period $t$ and $t+s$. We will show later that $\Lambda_{t+s}$ is a household's marginal utility in period $t+s$.

\subsection{Households}

All households are identical and have the same utility function:

$$
E\left[\sum_{t=0}^{\infty} \beta^{t} U\left(C_{t}, 1-N_{t}\right)\right],
$$

where $\beta \in(0,1)$ is the discount factor, and $U$ is a strictly increasing, strictly concave and continuously differentiable function that satisfies the usual Inada conditions. Each household chooses consumption $C_{t}$, labor supply $N_{t}$, and share holdings $\alpha_{t+1}^{j}$ to maximize utility (6) subject to the budget constraint:

$$
C_{t}+\int \alpha_{t+1}^{j}\left(P_{t}^{j}-D_{t}^{j}\right) d j=\int \alpha_{t}^{j} P_{t}^{j} d j+w_{t} N_{t}
$$


The first-order conditions are given by:

$$
\begin{aligned}
\Lambda_{t}\left(P_{t}^{j}-D_{t}^{j}\right) & =E_{t} \beta \Lambda_{t+1} P_{t+1}^{j}, \\
U_{1}\left(C_{t}, 1-N_{t}\right) & =\Lambda_{t}, \\
U_{2}\left(C_{t}, 1-N_{t}\right) & =\Lambda_{t} w_{t} .
\end{aligned}
$$

Equations (8)-(9) imply that the stock price $P_{t}^{j}$ is given by the discounted present value of dividends as in equation (5). In addition, $\Lambda_{t}$ is equal to the marginal utility of consumption.

\subsection{Competitive Equilibrium}

The sequences of quantities $\left\{I_{t}^{j}, N_{t}^{j}, K_{t}^{j}\right\}_{t \geq 0},\left\{C_{t}, N_{t}\right\}_{t \geq 0}$, and prices $\left\{w_{t}, P_{t}^{j}\right\}_{t \geq 0}$ for $j \in[0,1]$ constitute a competitive equilibrium if the following conditions are satisfied:

(i) Given prices $\left\{w_{t}\right\}_{t \geq 0},\left\{I_{t}^{j}, N_{t}^{j}\right\}_{t \geq 0}$ solves firm $j$ 's problem (5) subject to the law of motion (2).

(ii) Given prices $\left\{w_{t}, P_{t}^{j}\right\}_{t \geq 0},\left\{C_{t}, N_{t}, \alpha_{t+1}^{j}\right\}_{t \geq 0}$ maximizes utility in (6) subject to the budget constraint (7).

(iii) Markets clear in that:

$$
\begin{gathered}
\alpha_{t}^{j}=1, \\
N_{t}=\int N_{t}^{j} d j, \\
C_{t}+\int \frac{I_{t}^{j}}{z_{t}} d j+\int \xi_{t}^{j} K_{t}^{j} \mathbf{1}_{I_{t}^{j} \neq 0} d j=\int F\left(K_{t}^{j}, A_{t} N_{t}^{j}\right) d j .
\end{gathered}
$$

\section{Equilibrium Properties}

We start by analyzing a single firm's optimal investment policy, holding prices fixed. We then conduct aggregation and characterize equilibrium aggregate dynamics by a system of nonlinear difference equations. We show that the equilibrium is constrained efficient. Next, we analyze steady state and prove an exact irrelevance result. Finally, we log-linearize the equilibrium dynamic system and examine the conditions under which lumpy investment can be important.

\subsection{Optimal Investment Policy}

To simplify problem (5), we first solve a firm's static labor choice decision. Let $n_{t}^{j}=N_{t}^{j} / K_{t}^{j}$. The first-order condition with respect to labor yields:

$$
f^{\prime}\left(A_{t} n_{t}^{j}\right) A_{t}=w_{t}
$$


where we define $f(\cdot)=F(1, \cdot)$. This equation reveals that all firms choose the same laborcapital ratio in that $n_{t}^{j}=n_{t}=n\left(w_{t}, A_{t}\right)$ for all $j$. We can then derive firm $j$ 's operating profits:

$$
\max _{N_{t}^{j}} F\left(K_{t}^{j}, A_{t} N_{t}^{j}\right)-w_{t} N_{t}^{j}=R_{t} K_{t}^{j},
$$

where $R_{t}=f\left(A_{t} n_{t}\right)-w_{t} n_{t}$ is independent of $j$. Note that $R_{t}$ also represents the marginal product of capital because $F$ has constant returns to scale. Let $i_{t}^{j}=I_{t}^{j} / K_{t}^{j}$ denote firm $j$ 's investment rate. We can then express dividends in (4) as:

$$
D_{t}^{j}=\left[R_{t}-\frac{i_{t}^{j}}{z_{t}}-\xi_{t}^{j} \mathbf{1}_{i_{t}^{j} \neq 0}\right] K_{t}^{j}
$$

and rewrite (2) as

$$
K_{t+1}^{j}=\left[(1-\delta)+\Phi\left(i_{t}^{j}\right)\right] K_{t}^{j} .
$$

The above two equations imply that equity value or firm value are linear in capital $K_{t}^{j}$. We can then write firm value as $V_{t}^{j} K_{t}^{j}$ and rewrite problem (5) by dynamic programming:

$$
V_{t}^{j} K_{t}^{j}=\max _{i_{t}^{j}}\left[R_{t}-\frac{i_{t}^{j}}{z_{t}}-\xi_{t}^{j} \mathbf{1}_{i_{t}^{j} \neq 0}\right] K_{t}^{j}+E_{t}\left[\frac{\beta \Lambda_{t+1}}{\Lambda_{t}} V_{t+1}^{j} K_{t+1}^{j}\right],
$$

subject to (13). Substituting equation (13) into equation (14), we rewrite problem (14) as:

$$
V_{t}^{j}=\max _{i_{t}^{j}} R_{t}-\frac{i_{t}^{j}}{z_{t}}-\xi_{t}^{j} \mathbf{1}_{i_{t}^{j} \neq 0}+g\left(i_{t}^{j}\right) E_{t}\left[\frac{\beta \Lambda_{t+1}}{\Lambda_{t}} V_{t+1}^{j}\right],
$$

where we define:

$$
g\left(i_{t}^{j}\right)=1-\delta+\Phi\left(i_{t}^{j}\right)
$$

Note that $R_{t}$ and $\Lambda_{t}$ depend on the current aggregate state $\left(K_{t}, A_{t}, z_{t}\right)$ only. Suppose the equilibrium law of motion for aggregate capital is given by:

$$
K_{t+1}=G\left(K_{t}, A_{t}, z_{t}\right)
$$

Given this law of motion, the state variable for $V_{t}^{j}$ is $\left(K_{t}, A_{t}, z_{t}, \xi_{t}^{j}\right)$. We can write it as:

$$
V_{t}^{j}=V\left(K_{t}, A_{t}, z_{t}, \xi_{t}^{j}\right)
$$

for some function $V$. We aggregate each firm's price of capital $V_{t}^{j}$ and define the aggregate value of the firm per unit of capital conditioned on aggregate state $\left(K_{t}, A_{t}, z_{t}\right)$ as:

$$
\bar{V}_{t}=\bar{V}\left(K_{t}, A_{t}, z_{t}\right)=\int_{0}^{\xi_{\max }} V\left(K_{t}, A_{t}, z_{t}, \xi\right) \phi(\xi) d \xi
$$


for some function $\bar{V}$. Because $\xi_{t}^{j}$ is iid across both time and firms and is independent of aggregate shocks, we obtain:

$$
E_{t}\left[\frac{\Lambda_{t+1}}{\Lambda_{t}} V_{t+1}^{j}\right]=E_{t}\left[\frac{\Lambda_{t+1}}{\Lambda_{t}} \int_{0}^{\xi_{\max }} V\left(K_{t+1}, A_{t+1}, z_{t+1}, \xi\right) \phi(\xi) d \xi\right]=E_{t}\left[\frac{\Lambda_{t+1}}{\Lambda_{t}} \bar{V}_{t+1}\right],
$$

Now, we rewrite problem (15) as:

$$
V\left(K_{t}, A_{t}, z_{t}, \xi_{t}^{j}\right)=\max _{i_{t}^{j}} R_{t}-\frac{i_{t}^{j}}{z_{t}}-\xi_{t}^{j} \mathbf{1}_{i_{t}^{j} \neq 0}+g\left(i_{t}^{j}\right) E_{t}\left[\frac{\beta \Lambda_{t+1}}{\Lambda_{t}} \bar{V}_{t+1}\right] .
$$

Using this equation, we can characterize a firm's optimal investment policy by a generalized $(\mathrm{S}, \mathrm{s})$ rule (Caballero and Engel (1999)). In so doing, we first define marginal $Q$ as the (riskadjusted) present value of a marginal unit of investment:

$$
Q_{t}=E_{t}\left[\frac{\beta \Lambda_{t+1}}{\Lambda_{t}} \bar{V}_{t+1}\right]
$$

Since investment becomes productive with a one period delay, marginal $Q$ is equal to the discounted expected value of the firm of an additional unit of capital in the next period. In continuous time, the difference between marginal $Q$ and the aggregate price of capital $\bar{V}_{t+1}$ disappears. Because firm value is linearly homogeneous in capital, Tobin's average $Q$ is equal to the marginal $Q$ (Hayashi (1982)).

Equation (20) reveals that $g$ or $\Phi$ must be concave to determine optimal $i_{t}^{j}$. In addition, optimal $i_{t}^{j}$ is related to marginal $Q$ (Abel and Eberly (1994)). Without convex adjustment costs, $\Phi(x)=x$ and $i_{t}^{j}$ is indeterminate unless one assumes decreasing-returns-to-scale technology.

Proposition 1 Firm j's optimal investment policy is characterized by the $(S, s)$ policy in that there is a unique trigger value $\xi_{t}^{*}>0$ such that the firm invests if and only if $\xi_{t}^{j} \leq \min \left\{\xi_{t}^{*}, \xi_{\max }\right\}$. The trigger value $\xi_{t}^{*}$ satisfies the equation:

$$
\frac{\theta}{1-\theta} z_{t}^{\frac{1-\theta}{\theta}}\left(\psi Q_{t}\right)^{\frac{1}{\theta}}=\xi_{t}^{*}
$$

The optimal target investment level is given by:

$$
i_{t}^{j}=\left(\psi z_{t} Q_{t}\right)^{\frac{1}{\theta}} .
$$

When $\xi_{t}^{*} \leq \xi_{\max }$, marginal $Q$ satisfies:

$$
Q_{t}=E_{t}\left[\frac{\beta \Lambda_{t+1}}{\Lambda_{t}}\left\{R_{t+1}+(1-\delta+\varsigma) Q_{t+1}+\int_{0}^{\xi_{t+1}^{*}}\left[\xi_{t+1}^{*}-\xi\right] \phi(\xi) d \xi\right\}\right]
$$


Equation (22) says that, at the value $\xi_{t}^{*}$, the benefit from investment is equal to the fixed cost of investment. The benefit from investment increases with $Q_{t}$ and $z_{t}$. Thus, the investment trigger $\xi_{t}^{*}$ also increases with $Q_{t}$ and $z_{t}$. If $\xi_{t}^{*} \geq \xi_{\max }$, then the firm always invests. In the aggregate with a cross section of firms, this means that all firms decide to invest. In the analysis below, we will focus on an interior solution for which $\xi_{t}^{*}<\xi_{\max }$.

Note that the investment trigger $\xi_{t}^{*}$ depends on the aggregate state $\left(K_{t}, A_{t}, z_{t}\right)$ only. It does not depend on the firm-specific state $\left(K_{t}^{j}, \xi_{t}^{j}\right)$. This observation implies that conditioned on the aggregate state, the adjustment hazard, $\int_{0}^{\xi_{t}^{*}} \phi(\xi) d \xi$, is a constant. This result is due to our assumptions of competitive markets, constant-returns-to-scale production function, and the iid distribution of $\xi_{t}^{j}$. When the production function has decreasing returns to scale or there is monopoly power, the investment trigger $\xi_{t}^{*}$ and the adjustment hazard will depend on the firm-specific capital stock, as discussed in Caballero et al. (1995), Caballero and Engel (1999), and Khan and Thomas (2003, 2008).

Equation (23) implies that all firms choose an identical target investment level, which is inconsistent with empirical evidence on investment spikes (Cooper and Haltiwanger (2006)). One way to make investment targets depend on firm-specific characteristics is to introduce a persistent idiosyncratic productivity shock (Khan and Thomas (2008)). This extension will complicate our analysis significantly because in this case the investment trigger $\xi_{t}^{*}$ depends on the idiosyncratic productivity shock, which makes aggregation complicated. ${ }^{8}$

Equation (23) shows that the optimal investment level is positively related to marginal $Q$ if and only if the firm's idiosyncratic shock $\xi_{t}^{j}$ is lower than the trigger value $\xi_{t}^{*}$, conditioned on the aggregate state $\left(K_{t}, A_{t}, z_{t}\right)$. When $\xi_{t}^{j}>\xi_{t}^{*}$, firm $j$ chooses not to invest. This zero investment is unrelated to marginal $Q$. As a result, investment may not be related to marginal $Q$ in the presence of fixed adjustment costs, a point made by Caballero and Leahy (1996).

Equation (24) is a type of asset-pricing equation. Ignoring the integration term inside the conditional expectation operator in equation (24), this equation states that the expected price of capital or marginal $Q$ is equal to the risk-adjusted present value of the marginal product of capital. The integration term in (24) reflects the option value of waiting because of the fixed adjustment costs. When the shock $\xi_{t}^{j}>\xi_{t}^{*}$, it is not optimal to pay the fixed costs to make investment. Firms will wait to invest until $\xi_{t}^{j} \leq \xi_{t}^{*}$ and there is an option value of waiting.

\footnotetext{
${ }^{8}$ An alternative way is to introduce idiosyncratic investment-specific technology shocks. We have worked out this extension and proved an exact irrelevance proposition. The analysis is available upon request.
} 


\subsection{Aggregation and Equilibrium Characterization}

Given the linear homogeneity feature of firm value, we can conduct aggregation tractably. We define aggregate capital $K_{t}=\int K_{t}^{j} d j$, aggregate labor demand $N_{t}=\int N_{t}^{j} d j$, aggregate output $Y_{t}=\int Y_{t}^{j} d j$, and aggregate investment expenditure in consumption units $I_{t}=\int I_{t}^{j} / z_{t} d j$.

Proposition 2 The aggregate equilibrium sequences $\left\{Y_{t}, N_{t}, C_{t}, I_{t}, K_{t}, Q_{t}, \xi_{t}^{*}\right\}_{t \geq 0}$ are characterized by the following system of difference equations: ${ }^{9}$

$$
\begin{gathered}
\xi_{t}^{*}=\frac{\theta}{1-\theta} z_{t}^{\frac{1-\theta}{\theta}}\left(\psi Q_{t}\right)^{\frac{1}{\theta}}, \\
I_{t}=\left(\psi Q_{t}\right)^{\frac{1}{\theta}} z_{t}^{\frac{1-\theta}{\theta}}\left[\int_{0}^{\xi_{t}^{*}} \phi(\xi) d \xi\right] K_{t}, \\
K_{t+1}=(1-\delta+\varsigma) K_{t}+\frac{\psi}{1-\theta} K_{t}\left(z_{t} I_{t} / K_{t}\right)^{1-\theta}\left[\int_{0}^{\xi_{t}^{*}} \phi(\xi) d \xi\right]^{\theta}, \\
Y_{t}=F\left(K_{t}, A_{t} N_{t}\right)=I_{t}+C_{t}+K_{t} \int_{0}^{\xi_{t}^{*}} \xi \phi(\xi) d \xi, \\
\frac{U_{2}\left(C_{t}, 1-N_{t}\right)}{U_{1}\left(C_{t}, 1-N_{t}\right)}=A_{t} F_{2}\left(K_{t}, A_{t} N_{t}\right), \\
Q_{t}=E_{t} \frac{\beta U_{1}\left(C_{t+1}, 1-N_{t+1}\right)}{U_{1}\left(C_{t}, 1-N_{t}\right)}\left[F_{1}\left(K_{t+1}, A_{t+1} N_{t+1}\right)+(1-\delta+\varsigma) Q_{t+1}\right. \\
\left.\left.+\int_{0}^{\xi_{t+1}^{*}}\left(\xi_{t+1}^{*}-\xi\right) \phi(\xi) d \xi\right]\right\} .
\end{gathered}
$$

Equation (25) is identical to (22). We derive equations (26) and (27) by aggregating equations (2) and (23). Equation (26) shows that aggregate investment rate $I_{t} / K_{t}$ is positively related to marginal $Q$ as predicted by the standard $Q$-theory. However, unlike this theory, marginal $Q$ is not a sufficient statistic for the investment rate. In particular, the aggregate state $\left(K_{t}, A_{t}, z_{t}\right)$ also helps explain the aggregate investment rate besides marginal $Q$, via its effect on $\xi_{t}^{*}$.

Equation (28) is the resource constraint. The last term in the equation represents the aggregate fixed adjustment costs. The first equality of equation (28) gives aggregate output using a single firm's production function $F$. This result is primarily due to the constant returns to scale property of $F$. The representative household's consumption/leisure choice gives equation

\footnotetext{
${ }^{9}$ We omit the standard transversality conditions here.
} 
(29). Equation (30) is an asset pricing for the price of capital $Q$. It is obtained from equation (24). Note that by equations (26) and (25), we can show that the option value of waiting in the second line of $(30)$ is equal to $\frac{\theta}{1-\theta} \frac{I_{t+1}}{K_{t+1}}-\int_{0}^{\xi_{t}^{*}} \xi \phi(\xi) d \xi$.

\subsection{Constrained Efficiency}

Is the competitive equilibrium we studied efficient? To answer this question, we consider a social planner's problem in which he faces the same investment frictions as individual firms. Suppose the planner selects an investment trigger $\xi_{t}^{*}$ such that all firms make investments when the idiosyncratic fixed adjustment $\operatorname{cost}$ shock $\xi_{t} \leq \xi_{t}^{*}$. We can then aggregate individual firms' capital and investments to obtain the resource constraint (28) and the capital accumulation equation (27). The social planner's problem is to maximize the representative agent's utility (6) subject to these two equations.

Proposition 3 If $\phi^{\prime} \geq 0$, then the competitive equilibrium allocation and the investment trigger characterized in Proposition 2 are constrained efficient in the sense that they are identical to those obtained by solving a social planner's problem. In addition, the solution is unique.

The condition $\phi^{\prime} \geq 0$ and the assumptions for the preferences and technology given before ensure that the social planner's problem is a concave problem and hence it has a unique solution. Proposition 3 is important because we can use it to establish the existence of a recursive equilibrium for our economy by a standard argument as in Stokey and Lucas (1989). As a result, it provides the theoretic foundation for applying a recursive method to solve our model numerically. To the best of our knowledge, no similar result is proven in other models, e.g., the models in Khan and Thomas (2003, 2008) or Bachmann et al. (2008). In addition, it is also an open question whether or not a recursive equilibrium exists for these models.

\subsection{Steady State}

We consider a deterministic steady state in which there is no aggregate shock to labor augmenting technology and no aggregate shock to investment-specific technology, but there is still idiosyncratic fixed costs shock. In this case, steady-state aggregate variables $\left(Y, C, N, K, I, Q, \xi^{*}\right)$ are deterministic constants by a law of large numbers.

Proposition 4 Consider the lumpy investment model. Suppose $\delta>\varsigma$ and

$$
\delta-\varsigma<\frac{\xi_{\max }^{1-\theta} \psi}{(1-\theta)^{\theta} \theta^{(1-\theta)}} \int_{0}^{\xi_{\max }} \phi(\xi) d \xi .
$$


Then the steady-state investment trigger $\xi^{*} \in\left(0, \xi_{\max }\right)$ is the unique solution to the equation:

$$
\delta-\varsigma=\frac{\xi^{* 1-\theta} \psi}{(1-\theta)^{\theta} \theta^{(1-\theta)}} \int_{0}^{\xi^{*}} \phi(\xi) d \xi
$$

Given this value $\xi^{*}$, the steady-state value of $Q$ is given by:

$$
Q=\frac{1}{\psi}\left(\frac{\xi^{*}(1-\theta)}{\theta}\right)^{\theta}
$$

The other steady-state values $(I, K, C, N)$ satisfy:

$$
\begin{gathered}
\frac{I}{K}=(\delta-\varsigma)(1-\theta) Q, \\
F(K, N)=I+C+K \int_{0}^{\xi^{*}} \xi \phi(\xi) d \xi, \\
\frac{U_{2}(C, 1-N)}{U_{1}(C, 1-N)}=F_{2}(K, N), \\
Q=\frac{\beta}{1-\beta(1-\delta+\varsigma)}\left\{F_{1}(K, N)+\int_{0}^{\xi^{*}}\left(\xi^{*}-\xi\right) \phi(\xi) d \xi\right\} .
\end{gathered}
$$

The investment trigger $\xi^{*}$ is uniquely determined by equation (31), which states that, for the aggregate capital stock to be constant over time, new investment must offset capital depreciation. The steady-state aggregate price of capital is determined by equation (32), which follows from equation (25). At this price, a firm is just willing to pay the fixed cost to invest if the shock to its new investment just hits the trigger value $\xi^{*}$.

The other steady-state values $(I, K, C, N)$ are determined by a system of four equations (33)-(36). In particular, equation (33) implies that the steady-state investment rate increases with the aggregate price of capital $Q$. Equation (36) shows that $Q$ must satisfy a steady-state version of an asset-pricing equation, which states that it is equal to the present value of the marginal product of capital plus the option value of waiting.

We are unable to derive analytical comparative statics results for the steady sate values of $(I, K, C, N)$ under general conditions because they are determined by a system of four nonlinear equations. If we make some specific assumptions on preferences and technology, we have the following sharp comparative statics results:

Corollary 1 Consider the power function distribution with density $\phi(\xi)=\frac{\eta \xi^{\eta-1}}{\left(\xi_{\max }\right)^{\eta}}, \eta>0$. Assume that the parameter values are such that the inequality in (38) holds, i.e.,

$$
\xi_{\max }>\left[\psi^{-1}(\delta-\varsigma)(1-\theta)^{\theta} \theta^{(1-\theta)}\right]^{\frac{1}{1-\theta}}>0
$$


Then the steady-state trigger value is given by:

$$
\xi^{*}=\left[\psi^{-1}(\delta-\varsigma)(1-\theta)^{\theta} \theta^{(1-\theta)} \xi_{\max }^{\eta}\right]^{\frac{1}{\eta+1-\theta}} \in\left(0, \xi_{\max }\right) .
$$

In addition, consider the following specifications:

$$
\begin{aligned}
F(K, A N) & =K^{\alpha}(A N)^{1-\alpha}, \alpha \in(0,1), \\
U(C, 1-N) & =\left\{\begin{array}{cc}
\frac{C^{1-\gamma}}{1-\gamma} v(1-N) & \text { if } \gamma>0, \neq 1 \\
\log (C)+v(1-N) & \text { if } \gamma=1
\end{array}\right.
\end{aligned}
$$

where $v$ is strictly increasing, strictly concave, continuously differentiable, and satisfies the Inada conditions. Then the steady-state values $R / Q, I / Y, C / Y$ and $N$ are independent of $\xi_{\max }$. In addition,

$$
\begin{aligned}
\frac{\partial(I / K)}{\partial \xi_{\max }} & >0, \frac{\partial Q}{\partial \xi_{\max }}>0, \frac{\partial R}{\partial \xi_{\max }}>0, \frac{\partial w}{\partial \xi_{\max }}<0, \\
\frac{\partial K}{\partial \xi_{\max }} & <0, \frac{\partial Y}{\partial \xi_{\max }}<0, \frac{\partial C}{\partial \xi_{\max }}<0, \text { and } \frac{\partial I}{\partial \xi_{\max }}<0 .
\end{aligned}
$$

As $\xi_{\max }$ increases, the power function distribution is more spread out. Thus, less firms will adjust capital for a given investment trigger. To raise the aggregate investment rate to compensate capital depreciation, the steady-state investment trigger $\xi^{*}$ must rise, as shown in equation (38). As a result, the steady-state investment rate $I / K$ and $Q$ increase with $\xi_{\max }$. Under the additional assumptions on preferences and technology, both $I$ and $K$ decrease with $\xi_{\max }$, but $K$ decreases faster than $I$. This in turn implies that the steady-state output $Y$ and consumption $C$ decrease with $\xi_{\max }$. In addition, the steady-state rental rate of capital $R$ increases with $\xi_{\max }$, but the steady-state wage rate $w$ decreases with $\xi_{\max }$ because capital becomes relatively scarce.

The surprising result is that the steady-state values of $R / Q, I / Y, C / Y$ and $N$ are independent of $\xi_{\max }$. An important assumption for this result is that the distribution of the fixed costs is a power function, which has a homogeneity property. Our assumed functions for preferences and technology also have a homogeneity property. These two homogeneity properties are key to the independence result. We emphasize that the assumptions on preferences and technology in Corollary 1 are standard in macroeconomics and are consistent with balanced growth (e.g., King et al. (2002)). We next use Corollary 1 to study aggregate dynamics.

\subsection{An Exact Irrelevance Result}

We normalize an aggregate variable by its steady-state value characterized in Proposition 4 . We let $\tilde{X}_{t}=X_{t} / X$ denote this normalized value of $X_{t}$ when its deterministic steady-state value is $X$. We have the following irrelevance result: 
Proposition 5 Suppose the assumptions in Corollary 1 are satisfied. Then any maximal fixed cost $\xi_{\max }>0$ does not affect the equilibrium system of nonlinear difference equations that characterizes aggregate dynamics of the normalized variables $\left\{\tilde{Y}_{t}, \tilde{N}_{t}, \tilde{C}_{t}, \tilde{I}_{t}, \tilde{K}_{t}, \tilde{Q}_{t}, \tilde{\xi}_{t}^{*}\right\}_{t \geq 0}$.

Proposition 5 demonstrates that the maximal fixed cost $\xi_{\max }>0$ matters for aggregate dynamics only to the extent that it affects the steady state. The system of difference equations that characterizes the normalized variables relative to their steady-state values do not depend on $\xi_{\max }$. As a result, $\xi_{\max }$ does not affect the second moment and impulse response properties of the normalized aggregate variables or the logarithms of these variables.

The key to this proposition is that the system of nonlinear difference equations for the normalized equilibrium variables has a certain homogeneity property such that it is fully determined by the steady-state values $R / Q, I / Y, C / Y$ and $N$, and the model parameters other than $\xi_{\max }$. By Corollary 1, these steady state values are also independent of $\xi_{\max }$. Thus, the dynamic system is independent of $\xi_{\max }$. The key condition for this result is that the distribution of the idiosyncratic fixed cost shock is a power function. Other conditions are standard in the RBC literature. Note that the irrelevance proposition is still valid when we introduce maintenance investment as in Bachmann et al. (2008). The reason is that maintenance investment is proportional to the capital stock and thus still preserves the homogeneity property of the equilibrium system discussed above.

We emphasize that this result does not imply that aggregate dynamics with fixed adjustment $\operatorname{costs}\left(\xi_{\max }>0\right)$ are the same as those in a model without fixed adjustment $\operatorname{costs}\left(\xi_{\max }=0\right)$, because the dynamic systems of the (normalized) aggregate variables in the two models are different. That is, there is discontinuity when $\xi_{\max }$ moves from 0 to a positive number. Formally, when $\xi_{\max }$ goes to zero, the economy converges to the model without fixed adjustment costs. Its equilibrium system is given by:

$$
\begin{gathered}
I_{t}=\left(\psi Q_{t}\right)^{\frac{1}{\theta}} z_{t}^{\frac{1-\theta}{\theta}} K_{t} \\
K_{t+1}=(1-\delta+\varsigma) K_{t}+\frac{\psi}{1-\theta} K_{t}\left(z_{t} I_{t} / K_{t}\right)^{1-\theta}, \\
Y_{t}=F\left(K_{t}, A_{t} N_{t}\right)=I_{t}+C_{t} \\
\frac{U_{2}\left(C_{t}, 1-N_{t}\right)}{U_{1}\left(C_{t}, 1-N_{t}\right)}=A_{t} F_{2}\left(K_{t}, A_{t} N_{t}\right), \\
Q_{t}=E_{t}\left\{\frac{\beta U_{1}\left(C_{t+1}, 1-N_{t+1}\right)}{U_{1}\left(C_{t}, 1-N_{t}\right)}\left[F_{1}\left(K_{t+1}, A_{t+1} N_{t+1}\right)+(1-\delta+\varsigma) Q_{t+1}\right]\right\} .
\end{gathered}
$$


Clearly, the equilibrium system in Proposition 2 does not converge to the above system as $\xi_{\max } \rightarrow 0$ : For (28) to converge to (45), we need $\xi_{t}^{*}=0$. But this implies that $I_{t}=0$ by (26), which contradicts with (43).

Importantly, the shape of the fixed cost distribution plays an important role in the lumpy investment model. To analyze this issue more transparently, we next consider a log-linearized equilibrium system.

\subsection{Log-Linearized System}

We first note that the equilibrium wage rate $w_{t}=A_{t} F_{2}\left(K_{t}, A_{t} N_{t}\right)$ and the equilibrium gross interest rate $r_{t+1}$ satisfies $U_{1}\left(C_{t}, 1-N_{t}\right)=E_{t}\left[\beta U_{1}\left(C_{t+1}, 1-N_{t+1}\right) r_{t+1}\right]$. Using these two equations, we log-linearize the dynamic system given in Proposition 2 around the deterministic steady state and obtain the following proposition after some tedious algebra. We use $\hat{X}_{t}=$ $\left(X_{t}-X\right) / X$ to denote the deviation of a variable $X_{t}$ from its steady state value $X$.

Proposition 6 The log-linearized equilibrium dynamic system is given by:

$$
\begin{aligned}
& \hat{\xi}_{t}^{*}=\frac{1-\theta}{\theta} \hat{z}_{t}+\frac{1}{\theta} \hat{Q}_{t}, \\
& \hat{I}_{t}-\hat{K}_{t}=\left(\frac{1}{\theta} \hat{Q}_{t}+\frac{1-\theta}{\theta} \hat{z}_{t}\right)+\frac{\xi^{*} \phi\left(\xi^{*}\right)}{\int_{0}^{\xi^{*}} \phi(\xi) d \xi} \hat{\xi}_{t}^{*}, \\
& \hat{K}_{t+1}=(1-\delta+\varsigma) \hat{K}_{t}+\theta \hat{K}_{t}+(1-\theta)\left(\hat{I}_{t}+\hat{z}_{t}\right)+\frac{\theta \xi^{*} \phi\left(\xi^{*}\right)}{\int_{0}^{\xi^{*}} \phi(\xi) d \xi} \hat{\xi}_{t}^{*}, \\
& \hat{Y}_{t}=\frac{F_{1} K}{Y} \hat{K}_{t}+\left(1-\frac{F_{1} K}{Y}\right)\left[\hat{A}_{t}+\hat{N}_{t}\right] \\
& \hat{Y}_{t}=\frac{I}{Y} \hat{I}_{t}+\frac{C}{Y} \hat{C}_{t}+\left(1-\frac{I}{Y}-\frac{C}{Y}\right)\left[\hat{K}_{t}+\frac{\left(\xi^{*}\right)^{2} \phi\left(\xi^{*}\right)}{\int_{0}^{\xi^{*}} \xi \phi(\xi) d \xi} \hat{\xi}_{t}^{*}\right], \\
& \hat{Q}_{t}=\beta E_{t} \hat{Q}_{t+1}-E_{t} \hat{r}_{t+1}+\beta(\delta-\varsigma)(1-\theta) E_{t} \hat{z}_{t+1} \\
& +\frac{-F_{11} F_{2}}{F_{21} F_{1}} \frac{\beta R}{Q} E_{t}\left[\hat{A}_{t+1}-\hat{w}_{t+1}\right] \text {, } \\
& E_{t} \hat{r}_{t+1}=u_{C, C} \hat{C}_{t}-u_{C, N} \hat{N}_{t}-E_{t}\left(u_{C, C} \hat{C}_{t+1}-u_{C, N} \hat{N}_{t+1}\right), \\
& \hat{w}_{t}=\left(u_{N, C}-u_{C, C}\right) \hat{C}_{t}+\left(u_{C, N}-u_{N, N}\right) \hat{N}_{t} \\
& =\frac{K F_{21}}{F_{2}} \hat{K}_{t}+\frac{N F_{22}}{F_{2}} \hat{N}_{t}+\left(1+\frac{N F_{22}}{F_{2}}\right) \hat{A}_{t},
\end{aligned}
$$

where we denote $u_{N, C}=\frac{C U_{21}(C, 1-N)}{U_{2}(C, 1-N)}, u_{N, N}=\frac{N U_{22}(C, 1-N)}{U_{2}(C, 1-N)}, u_{C, C}=\frac{C U_{11}(C, 1-N)}{U_{1}(C, 1-N)}$, and $u_{C, N}=$ $\frac{N U_{12}(C, 1-N)}{U_{1}(C, 1-N)}$. 
This proposition demonstrates explicitly how parameters for preferences, technology, and the fixed cost distribution determine the log-linearized equilibrium system. Equation (48) shows that changes in the investment-specific technology shock or in the price of capital determine changes in the investment trigger, and thus changes in the likelihood of capital adjustment and in the number of adjustors. This effect is often referred to as the extensive margin effect. Equation (49) shows that changes in the aggregate investment rate are determined by an intensive margin effect and an extensive margin effect. The intensive margin effect represented by the expression in the bracket on the right hand side of (49) determines the size of the aggregate investment rate. The magnitude of the extensive margin effect on the aggregate investment rate is determined by the steady-state elasticity of the adjustment rate with respect to the investment trigger, $\xi^{*} \phi\left(\xi^{*}\right) / \int_{0}^{\xi^{*}} \phi(\xi) d \xi$. In order for lumpy investment to matter for business cycles, the extensive margin effect must be large. This requires the elasticity of the adjustment rate with respect to the investment trigger to be large. ${ }^{10}$ We will give some examples in the next section to illustrate this point.

Both the intensive margin and extensive margin effects are affected by the general equilibrium price movements because changes in the wage rate and in the interest rate affect the changes in the price of capital, as revealed by equation (53). The change in the interest rate is determined by preferences. As equation (54) shows, when the elasticity of intertemporal substitution is larger, the consumption smoothing incentive is weaker, leading to a smaller interest rate movement.

The magnitude of the wage movements is determined by the preferences and technology parameters as revealed by equation (55). Equation (53) shows that the wage feedback effect is magnified by the steady-state ratio of the marginal product of capital to $Q$ or $R / Q$. Because the steady-state $Q$ is equal to the present value of $R$ and the option value of waiting as revealed by (36), the larger is the option value of waiting, the smaller is $R / Q$. We can show that holding the adjustment rate and the investment trigger fixed, if more low fixed costs have high probabilities or the fixed cost distribution is more right skewed, the option value of waiting is higher. In this case, $R / Q$ is smaller and thus the wage feedback effect is smaller.

In summary, both the micro-level investment lumpiness and the general equilibrium price movements are important to determine aggregate dynamics. The relative importance of these two effects is determined by the preference and technology parameters and the distribution of the idiosyncratic fixed cost shock. In particular, holding preferences and technology fixed, if

\footnotetext{
${ }^{10}$ Even though this elasticity is an "endogenous" concept, we can compute it ex post in equilibrium. For the power function distribution, the elasticity is equal to the shape parameter, which is exogenous.
} 
the steady-state elasticity of the adjustment rate is larger, then the extensive margin effect is stronger. If the fixed cost distribution is more right skewed, then the general equilibrium wage feedback effect is weaker.

\section{Numerical Results}

We evaluate our lumpy investment model quantitatively and compare this model with two benchmark models. The first one is obtained by removing fixed adjustment costs only $\left(\xi_{t}^{j}=0\right)$. We call this model the partial adjustment model. Its equilibrium system is given by (43)-(47). The second one is a frictionless $R B C$ model, obtained by removing all adjustment costs in the model presented in Section 2. Its equilibrium system is obtained by setting $\theta=\varsigma=0$ and $\psi=1$ in (44)-(47) and $Q_{t}=1 / z_{t}$. In both benchmark models, all firms make identical decisions, and thus these models are equivalent to standard representative-firm RBC models (e.g., Fisher (2006) and Greenwood et al. (2000)). Because we have characterized the equilibria for all three models by systems of nonlinear difference equations as shown in the previous section, we can use the standard second-order approximation method to solve the models numerically. ${ }^{11}$ To do so, we need first to calibrate the models.

\subsection{Baseline Parametrization}

For all model economies, we take the Cobb-Douglas production function, $F(K, A N)=K^{\alpha}(A N)^{1-\alpha}$, and the period utility function, $U(C, 1-N)=\log (C)-a N$, where $a>0$ is a parameter. We fix the length of period to correspond to one year, as in Thomas (2002), and Khan and Thomas (2003, 2008). Annual frequency allows us to use empirical evidence on establishment-level investment in selecting parameters for the fixed adjustment costs and the distribution of idiosyncratic investment-specific shocks.

We first choose parameter values for preferences and technology to ensure that the steadystate of the frictionless RBC model is consistent with the long-run values of key postwar U.S. aggregates. Specifically, we set the subjective discount factor to $\beta=0.96$, so that the implied annual real interest rate is 4 percent (Prescott (1986)). We choose the value of $a$ so that the steady-state hours are about $1 / 3$ of available time spent in market work. We set the capital share $\alpha=0.36$, implying a labor share of 0.64 , which is close to the labor income share in the NIPA. We take the depreciate rate $\delta=0.1$, as in the literature on business cycles (e.g., Prescott (1986)).

\footnotetext{
${ }^{11}$ The Dynare code is available upon request.
} 
It is often argued that convex adjustment costs are not observable directly and hence cannot be calibrated based on average data over the long run (e.g., Greenwood et al. (2000)). Thus, we impose the two restrictions:

$$
\psi=\delta^{\theta} \text { and } \varsigma=\frac{-\theta}{1-\theta} \delta,
$$

so that the partial adjustment model and the frictionless RBC model give identical steady-state allocations. ${ }^{12}$ As in our paper, Baxter and Crucini (1993), Jermann (1998), and Greenwood et al. (2000) make similar assumptions for the parameters in the adjustment cost function. We assume condition (56) throughout our numerical experiments below.

We next follow Khan and Thomas (2003) to select parameters for the aggregate shocks. They use Stock and Watson (1999) data set to estimate the persistence and volatility of the Solow residuals equal to 0.9225 and 0.0134 , respectively. Transforming the total factor productivity shocks to our labor-augmenting technology shocks, we set $\rho_{A}=0.9225$ and $\sigma_{A}=0.0134 / 0.64=0.021$. As in Khan and Thomas (2003), we set $\rho_{z}=0.706$ and $\sigma_{z}=0.017$ in the investment-specific technology shock process. Following Kiyotaki and West (1996), Thomas (2002), and Khan and Thomas (2003), we set $\theta=1 / 5.98$, implying that the $Q$-elasticity of the investment rate is 5.98 .

We adopt the power function distribution for the idiosyncratic fixed cost shock. We need to calibrate two parameters $\xi_{\max }$ and $\eta$. We try to match micro-level evidence on the investment lumpiness reported by Cooper and Haltiwanger (2006). Cooper and Haltiwanger (2006) find that the inaction rate is 0.081 and the positive spike rate is about 0.186 . A positive investment spike is defined as the investment rate exceeding 0.2. For the power function distribution, the steady-state inaction rate is given by $1-\left(\xi^{*} / \xi_{\max }\right)^{\eta}$ and the steady-state investment rate is given by equation (33). Because our model implies that the target investment rate $I / K$ is identical for all firms, our model cannot match the spike rate. Therefore, there are many combinations of $\eta$ and $\xi_{\max }$ to match the inaction rate. As baseline values, we follow Khan and Thomas $(2003,2008)$ and take a uniform distribution $(\eta=1)$. This implies that $\xi_{\max }=0.0242$. In this case, total fixed adjustment costs account for 2.4 percent of output, 10 percent of total investment spending and 1.0 percent of capital stock, which are reasonable according to the estimation by Cooper and Haltiwanger (2006).

We summarize the baseline parameter values in Table 1.

\footnotetext{
${ }^{12}$ Under the log-linear approximation method, only the curvature parameter $\theta$ in the convex adjustment cost function matters for the approximated equilibrium dynamics.
} 
Table 1. Baseline Parameter Vales

\begin{tabular}{lllllllllll}
\hline$\beta$ & $a$ & $\alpha$ & $\delta$ & $\rho_{A}$ & $\sigma_{A}$ & $\rho_{z}$ & $\sigma_{z}$ & $\theta$ & $\xi_{\max }$ & $\eta$ \\
0.9615 & 2.5843 & 0.36 & 0.1 & 0.9225 & 0.021 & 0.706 & 0.017 & $1 / 5.98$ & 0.0242 & 1 \\
\hline
\end{tabular}

\subsection{Partial Equilibrium Dynamics}

In order to understand the general equilibrium effects of fixed costs on business cycles, we start with a partial equilibrium analysis by fixing the wage rate and the interest rate at their steady state values. For the power function distribution, we can show that the elasticity of the adjustment rate is equal to $\eta$. Using assumption (56), the specification of the utility function and the production function, and setting $\hat{w}_{t}=\hat{r}_{t}=0$, we can rewrite equations (49) and (53) as:

$$
\begin{gathered}
\hat{I}_{t}-\hat{K}_{t}=\underbrace{\frac{1}{\theta} \hat{Q}_{t}+\frac{1-\theta}{\theta} \hat{z}_{t}}_{\text {intensive }}+\underbrace{\eta \hat{\xi}_{t}^{*}}_{\text {extensive }} \\
\hat{Q}_{t}=\beta E_{t} \hat{Q}_{t+1}+\delta \beta E_{t} \hat{z}_{t+1}+\left[1-\left(1-\frac{\delta}{1-\theta}\right) \beta-\frac{\beta \theta \delta}{1-\theta} \frac{1}{1+\eta}\right] \frac{1-\alpha}{\alpha} E_{t} \hat{A}_{t+1} .
\end{gathered}
$$

The last term in the square bracket in equation (58) represents the option value of waiting in the presence of fixed costs. The log-linearized system for the partial adjustment model with fixed prices is obtained by setting $\eta=0$ and ignoring equation (48).

We now analyze the impulse response properties based on the above log-linearized system. Figure 1 plots the impulse responses to a positive one standard deviation shock to the laboraugmenting technology (N-shock). Following this shock, the marginal product capital rises. Thus, the price of capital or the marginal $Q$ rises. Because there is an option value of waiting, the increase in $Q$ is higher in the lumpy investment model than in the partial adjustment model. The increase in $Q$ has both intensive and extensive margin effects in the lumpy investment model as revealed by equation (49). In particular, it raises the adjustment rate by 11 percent in the lumpy investment model. Due to this extensive margin effect, the increase in the investment rate in the lumpy investment model is higher than that in the partial adjustment model (22 percent versus 10 percent).

\section{[Insert Figures 1-2 Here.]}

Figure 2 plots the impulse responses to a positive one standard deviation shock to the investment-specific technology (I-shock). Following this shock, the marginal $Q$ rises by the same magnitude in both the lumpy investment and in the partial adjustment model because 
these two models deliver an identical coefficient of $\hat{z}_{t}$ in (58). Even though the increase in marginal $Q$ is identical, the investment rate increases much more in the lumpy investment model than in the partial adjustment model (15 percent versus 8 percent). The reason is that the investment-specific technology shock has a direct extensive margin effect by raising the adjustment rate (see equation (48)). In particular, the adjustment rate rises by about 8 percent.

\subsection{General Equilibrium Dynamics}

We now turn to general equilibrium dynamics by endogenizing the prices. In this case, the general equilibrium price movements play an important role in shaping aggregate dynamics. To see this, we write the log-linearized equation for the marginal $Q$ as:

$$
\begin{aligned}
\hat{Q}_{t}= & \beta E_{t} \hat{Q}_{t+1}+\beta \delta E_{t} \hat{z}_{t+1}-E_{t}\left[\hat{r}_{t+1}\right] \\
& +\left[1-\left(1-\frac{\delta}{1-\theta}\right) \beta-\frac{\beta \theta \delta}{1-\theta} \frac{1}{1+\eta}\right] \frac{1-\alpha}{\alpha} E_{t}\left[A_{t+1}-\hat{w}_{t+1}\right],
\end{aligned}
$$

where the equilibrium interest rate and wage rate satisfy

$$
\begin{gathered}
E_{t}\left[\hat{r}_{t+1}\right]=E_{t}\left[\hat{C}_{t+1}\right]-\hat{C}_{t}, \\
\hat{w}_{t}=\hat{C}_{t}=(1-\alpha) \hat{A}_{t}+\alpha\left(\hat{K}_{t}-\hat{N}_{t}\right) .
\end{gathered}
$$

In general equilibrium, a positive N-shock or I-shock raises the interest rate and the wage rate, and thus dampens the increases in marginal $Q$ or the price of capital, as revealed by equation (59). As a result, both the extensive and intensive margin effects are weakened in general equilibrium. Thomas (2002) and Khan and Thomas (2003, 2008) emphasize this general equilibrium effect. They also find that movements in interest rates and wages yield quantity dynamics that are virtually indistinguishable from a standard RBC model without fixed adjustment costs. However, we do not obtain this finding because they use different numerical methods than ours. Their models are also different than ours in that they assume long-run growth and a decreasing-returns-to-scale technology. In addition, fixed costs in their models are measured in terms of labor costs rather than capital.

\section{[Insert Figures 3-4 Here.]}

Figures 3-4 plot impulse responses to a positive one standard deviation N-shock. Compared to Figure 1, the increase in the investment rate is about 10 times smaller in general equilibrium for the lumpy investment and partial adjustment models than that in partial equilibrium. In 
addition, the responses in the lumpy investment and partial adjustment models are similar, but the lumpy investment model brings predictions closer to those of the frictionless RBC model. The intuition is that the partial adjustment model implies too sluggish responses of investment due to convex adjustment costs. The extensive margin effect in the lumpy investment model raises the responses of investment to shocks. But the price feedback effect partially offsets this extensive margin effect. Figure 4 shows that both the interest rate and the wage rate rise. As a result, the increase in marginal $Q$ in the lumpy investment model is much smaller in general equilibrium than in partial equilibrium ( 0.1 percent versus 1.8 percent). This in turn causes the adjustment rate to rise by less than 1 percent as revealed in Figure 3, compared to 11 percent in partial equilibrium.

\section{[Insert Figures 5-6 Here.]}

Figures 5-6 plot the impulse responses to a positive one standard deviation I-shock. Comparing with Figure 2, we find that the effects on the investment rate is much smaller in general equilibrium than in partial equilibrium. In addition, the impulse responses in the lumpy investment and the partial adjustment model are similar. In contrast to the partial equilibrium case, a positive I-shock lowers marginal $Q$ in both the lumpy investment and partial adjustment models. The intuition follows from equation (59) and Figure 6. The increase in the interest rate and the wage rate lowers the profitability of the firm and hence raises the cost of investment. This effect dominates the positive effect of investment-specific technology shock on $Q$. Why do the investment rate and the adjustment rate still rise? The reason is that the increase in the I-shock decreases the price of new investment. Thus, it has a direct positive effect on the investment trigger and the investment rate as revealed by equations (48) and (49), respectively. ${ }^{13}$ However, the effect is smaller than that in partial equilibrium, due to the powerful general equilibrium price feedback effect. Figure 5 shows that the adjustment rate rises by 1.5 percent only, which is much smaller than 8 percent in partial equilibrium.

Next, we turn to the business cycle moments properties. Table 2 presents standard deviations, autocorrelations, and contemporaneous correlations for several model economies. We first consider the result for the frictionless RBC and partial adjustment models. It is well known that the partial adjustment model delivers less volatile and more persistent equilibrium quantities and prices than the frictionless RBC model because of the smoothing role of the convex adjustment costs. We then introduce fixed costs into the partial adjustment model. Rows

\footnotetext{
${ }^{13}$ In contrast to the N-shock, the initial response of consumption is negative because investment crowds out consumption as typical in models with investment-specific technology shocks.
} 
labelled "Lumpy1" in Table 2 present the result for this lumpy investment model with the baseline parameter values. They reveal that although impulse responses in the partial adjustment model and the lumpy investment model are similar, the difference in the model predicted second moments is non-negligible. The lumpy investment model delivers higher volatility in all quantities and prices than the partial adjustment model as revealed in Panel A. In particular, aggregate investment, the investment rate, and hours are 16, 13, and 28 percent, respectively, more volatile in the lumpy investment model than in the partial adjustment model. Panel B of Table 2 shows that the lumpy investment model predicts less persistent equilibrium quantities and prices, which are closer to the predictions of the frictionless RBC model. Panel C of Table 2 presents contemporaneous correlations with output. Marginal $Q$ is negatively correlated with output for all models because a positive investment-specific technology shock lowers the price of capital directly. All other quantities and prices move positively with output. In summary, Table 2 demonstrates that the predictions of the lumpy investment model are closer to those of the standard frictionless RBC model. Thus, it also suffers from a number of difficulties in matching the US business cycle facts, as in the standard frictionless RBC model. Thomas (2002) reports a similar finding.

So far, we have shown that under the baseline calibration, the general equilibrium price movements dampen the extensive margin effect significantly, making predictions of the lumpy investment model and the partial adjustment model similar. We now illustrate that the shape parameter of the distribution function of the idiosyncratic shock is important for the extensive margin effect. We set $\eta=20$ and re-calibrate $\xi_{\max }=0.02232$ such that the inaction rate is equal to 0.081 . In this case, the elasticity of the adjustment rate is 20 times of that in the baseline calibration so that the extensive margin effect is much larger. Of course, this calibration is unreasonable because total fixed costs are too large, accounting for 4.3 percent of output, 19.1 percent of total investment spending, and 1.9 percent of capital stock.

Rows labelled "Lumpy2" in Table 2 present the result for this calibration. The result reveals that the difference between the lumpy investment model and the partial adjustment model becomes larger. In particular, aggregate investment in the lumpy investment model is 40 percent more volatile than in the partial adjustment model. The investment rate in the lumpy investment model is 46 percent more volatile than in the partial adjustment model. However, the differences in the autocorrelations and contemporaneous correlations across these two models are small.

Gourio and Kashyap (2007) argue that for the extensive margin effect to be large in the Thomas (2002) model, the fixed cost distribution must be sufficiently compressed in the sense 
Table 2. Business Cycle Moments

\begin{tabular}{|c|c|c|c|c|c|c|c|c|}
\hline & $Y$ & $C$ & $I$ & $N$ & $Q$ & $I / K$ & $r$ & $w$ \\
\hline & \multicolumn{8}{|c|}{ A. Standard deviations (percentage) } \\
\hline PA & 2.27 & 2.03 & 4.09 & 0.87 & 1.18 & 3.74 & 0.28 & 2.03 \\
\hline Lumpy1 & 2.41 & 2.12 & 4.74 & 1.11 & 1.22 & 4.41 & 0.36 & 2.12 \\
\hline Lumpy2 & 2.60 & 2.24 & 5.72 & 1.45 & 1.36 & 5.45 & 0.48 & 2.24 \\
\hline LumpyGK & 2.59 & 2.22 & 5.44 & 1.46 & 1.32 & 5.11 & 0.46 & 2.22 \\
\hline \multirow[t]{2}{*}{$\mathrm{RBC}$} & 2.81 & 2.36 & 7.58 & 1.95 & 1.67 & 7.46 & 0.60 & 2.36 \\
\hline & \multicolumn{8}{|c|}{ B. Autocorrelations } \\
\hline $\mathrm{PA}$ & 0.94 & 0.96 & 0.77 & 0.63 & 0.83 & 0.68 & 0.63 & 0.96 \\
\hline Lumpy1 & 0.93 & 0.96 & 0.73 & 0.60 & 0.78 & 0.64 & 0.60 & 0.96 \\
\hline Lumpy2 & 0.91 & 0.95 & 0.67 & 0.56 & 0.70 & 0.58 & 0.56 & 0.95 \\
\hline LumpyGK & 0.92 & 0.95 & 0.70 & 0.58 & 0.72 & 0.61 & 0.58 & 0.95 \\
\hline \multirow[t]{2}{*}{$\mathrm{RBC}$} & 0.89 & 0.93 & 0.64 & 0.57 & 0.70 & 0.58 & 0.57 & 0.93 \\
\hline & \multicolumn{8}{|c|}{ C. Contemporaneous correlations with output } \\
\hline PA & 1 & 0.92 & 0.83 & 0.45 & -0.21 & 0.33 & 0.09 & 0.92 \\
\hline Lumpy1 & 1 & 0.89 & 0.81 & 0.47 & -0.32 & 0.34 & 0.20 & 0.89 \\
\hline Lumpy2 & 1 & 0.83 & 0.80 & 0.51 & -0.43 & 0.37 & 0.32 & 0.83 \\
\hline LumpyGK & 1 & 0.83 & 0.83 & 0.51 & -0.42 & 0.39 & 0.32 & 0.83 \\
\hline $\mathrm{RBC}$ & 1 & 0.73 & 0.78 & 0.56 & -0.53 & 0.43 & 0.44 & 0.73 \\
\hline
\end{tabular}

Notes: All variables are in logarithms. RBC: the standard real business cycle model. PA: the partial adjustment model. Lumpy1: our lumpy investment model under the baseline calibration in Table 1. Lumpy2: our lumpy investment model with power function distribution where $\eta=20$ and $\xi_{\max }=0.02232$. LumpyGK: our lumpy investment model with our calibrated Gourio and Kashyap (2007) distribution. 
that many firms must face nearly identical fixed costs. We have argued in Proposition 6 that the key determinant of the extensive margin effect is the steady-state elasticity of the adjustment rate, but not the compression property. We now take the Gourio and Kashyap (2007) distribution $H\left(\xi / \xi_{\max }\right)$ in our lumpy investment model, where $H(x)=\frac{h(x)-h(0)}{h(1)-h(0)}$ and $h(x)=\left[\arctan \left(\sigma_{1}(x-\chi)\right)+\arctan \left(\sigma_{2}(x-1)\right)\right] /(2 \pi)$, for $\chi \in(0,1)$. This distribution has the property that most firms bunch around $\xi_{\max }$ and $\chi \xi_{\max }$. As in Gourio and Kashyap (2007), we set $\sigma_{1}=150$ and $\sigma_{2}=33.3$. Unlike their distribution with $\chi=0.5$, we set $\chi=0.05$ so that there are many firms having small fixed costs at the size of 5 percent of $\xi_{\max }$. We then set $\xi_{\max }=0.022494$ to match the inaction rate of 0.081 . In this case, total fixed costs are smaller than those in our baseline calibration. They account for 1.42 percent of output, 5.75 percent of total investment spending, and 0.58 percent of capital stock. However, the effect of lumpy investment is much larger than in the baseline calibration, as shown in Table 2.

Rows labelled "LumpyGK" in Table 2 present the result for the Gourio-Kashyap distribution. We find that our calibrated Gourio-Kashyap distribution and the power function distribution with $\eta=20$ deliver similar second moments, but the former distribution gives slightly less volatile investment and investment rate. To see the intuition, we compute the steady-state elasticities of the adjustment rate with respect to the investment trigger for the Gourio-Kashyap distribution and for the power function distribution. We find they are equal to 6.28 and 20 respectively. As a result, the extensive margin effect for the Gourio-Kashyap distribution is smaller, justifying less volatile investment. But why is the difference in equilibrium second moments for the two distributions so small? The intuition comes from the general equilibrium price feedback effect. As Proposition 6 shows, the magnitude of the wage feedback effect is determined by the state-steady ratio $R / Q$. We find that it is equal to 0.145 for the Gourio-Kashyap distribution, which is smaller than the value 0.159 for the power function distribution with $\eta=20$, because the Gourio-Kashyap distribution is more right skewed than the power function distribution. Thus, the price feedback effect is smaller for the Gourio-Kashyap distribution, which makes the powerful dampening effect on investment much smaller.

\section{Conclusion}

We have presented an analytically tractable general equilibrium business cycle model that features micro-level investment lumpiness. We prove that a competitive equilibrium exists and is unique and constrained efficient. We also prove an exact irrelevance proposition, which states that under some conditions aggregate dynamics are identical for any positive upper support 
of the fixed cost distribution. Within our framework, we give conditions under which lumpy investment can be important to a first-order approximation. Essentially, we need the fixed cost distribution to satisfy two conditions: (i) The steady-state elasticity of the adjustment rate is large so that the extensive margin effect is large. (ii) The fixed cost distribution is right skewed so that the general equilibrium price feedback is small. We show numerically that introducing fixed costs to a model with convex adjustment costs raises business cycle volatility, but reduces persistence of output, consumption, investment, and hours. In addition, when lumpy investment becomes more important, it brings business cycle moments closer to those in the standard frictionless RBC model.

Our model serves as a theoretical benchmark for understanding the general equilibrium effect of lumpy investment. It can be used as a benchmark to check the accuracy of various numerical methods applied in the lumpy-investment literature. Our model is stylized and not designed to match all micro-level and macro-level empirical evidence. One limitation of our model is that it is not suitable for addressing distributional asymmetry and aggregate nonlinearity. To address this issue, it is necessary to relax the assumption of constant returns to scale. In this case, the distribution of capital is a state variable and we are unable to derive a closed-form solution. One has to use a numerical method to approximate the distribution of capital. It would be interesting to apply and compare various recently developed numerical methods reviewed in den Haan (2010a). 


\section{Appendix}

\section{A Proofs}

Proof of Proposition 1: From (20), we can show that the target investment level $i_{t}^{j}$ satisfies the first-order condition:

$$
\frac{1}{z_{t}}=g^{\prime}\left(i_{t}^{j}\right) E_{t}\left[\frac{\beta \Lambda_{t+1}}{\Lambda_{t}} \bar{V}_{t+1}\right] .
$$

By equations (3), (16) and (21), we can derive equation (23). Using this equation, we define $V^{a}\left(K_{t}, A_{t}, z_{t}, \xi_{t}^{j}\right)$ as the price of capital when the firm chooses to invest. It is given by:

$$
\begin{aligned}
V^{a}\left(K_{t}, A_{t}, z_{t}, \xi_{t}^{j}\right)= & R_{t}-\frac{i_{t}^{j}}{z_{t}}-\xi_{t}^{j}+g\left(i_{t}^{j}\right) Q_{t} \\
= & R_{t}+(1-\delta+\varsigma) Q_{t} \\
& +\frac{\theta}{1-\theta} z_{t}^{\frac{1-\theta}{\theta}}\left(\psi Q_{t}\right)^{\frac{1}{\theta}}-\xi_{t}^{j}
\end{aligned}
$$

Define $V^{n}\left(K_{t}, A_{t}, z_{t}\right)$ as the price of capital when the firm chooses not to invest. It satisfies:

$$
V^{n}\left(K_{t}, A_{t}, z_{t}\right)=R_{t}+(1-\delta+\varsigma) Q_{t},
$$

which is independent of $\xi_{t}^{j}$. We can then rewrite problem (20) as:

$$
V\left(K_{t}, A_{t}, z_{t}, \xi_{t}^{j}\right)=\max \left\{V^{a}\left(K_{t}, A_{t}, z_{t}, \xi_{t}^{j}\right), V^{n}\left(K_{t}, A_{t}, z_{t}\right)\right\} .
$$

Clearly, there is a unique cutoff value $\xi_{t}^{*}$ given in (22) satisfying the condition:

$$
\begin{gathered}
V^{a}\left(K_{t}, A_{t}, z_{t}, \xi_{t}^{*}\right)=V^{n}\left(K_{t}, A_{t}, z_{t}\right) \\
V^{a}\left(K_{t}, A_{t}, z_{t}, \xi_{t}^{j}\right) \geq V^{n}\left(K_{t}, A_{t}, z_{t}\right) \text { if and only if } \xi_{t}^{j} \leq \xi_{t}^{*} .
\end{gathered}
$$

Because the support of $\xi_{t}^{j}$ is $\left[0, \xi_{\max }\right]$, the investment trigger is given by $\min \left\{\xi_{t}^{*}, \xi_{\max }\right\}$.

When $\xi_{t}^{*} \leq \xi_{\max }$, we show that:

$$
\begin{aligned}
\bar{V}_{t} & =\int_{0}^{\xi_{\max }} V\left(K_{t}, A_{t}, z_{t}, \xi\right) \phi(\xi) d \xi \\
& =\int_{\xi_{t}^{*}}^{\xi_{\max }} V^{n}\left(K_{t}, A_{t}, z_{t}\right) \phi(\xi) d \xi+\int_{0}^{\xi_{t}^{*}} V^{a}\left(K_{t}, A_{t}, z_{t}, \xi\right) \phi(\xi) d \xi \\
& =V^{n}\left(K_{t}, A_{t}, z_{t}\right)+\int_{0}^{\xi_{t}^{*}}\left[V^{a}\left(K_{t}, A_{t}, z_{t}, \xi\right)-V^{n}\left(K_{t}, A_{t}, z_{t}\right)\right] \phi(\xi) d \xi .
\end{aligned}
$$


We use equations (A.2), (A.3) and (22) to derive

$$
\begin{aligned}
V^{a}\left(K_{t}, A_{t}, z_{t}, \xi\right)-V^{n}\left(K_{t}, A_{t}, z_{t}\right) & =\frac{\theta}{1-\theta} z_{t}^{\frac{1-\theta}{\theta}}\left(\psi Q_{t}\right)^{\frac{1}{\theta}}-\xi \\
& =\xi_{t}^{*}-\xi
\end{aligned}
$$

Using the above two equations, (A.3), and (21), we obtain (24). Q.E.D.

Proof of Proposition 2: From (12), we deduce that all firms choose the same labor-capital ratio $n_{t}$. We thus obtain $N_{t}=n_{t} K_{t}$. We then derive

$$
\begin{aligned}
Y_{t} & =\int Y_{t}^{j} d j=\int F\left(K_{t}^{j}, A_{t} N_{t}^{j}\right) d j=\int F\left(1, A_{t} n_{t}^{j}\right) K_{t}^{j} d j \\
& =F\left(1, A_{t} n_{t}\right) \int K_{t}^{j} d j=F\left(1, A_{t} n_{t}\right) K_{t}=F\left(K_{t}, A_{t} N_{t}\right),
\end{aligned}
$$

which gives the first equality in equation (28). As a result, we use equation (12) and $n_{t}^{j}=n_{t}$ to show:

$$
A_{t} F_{2}\left(K_{t}, A_{t} N_{t}\right)=w_{t}
$$

By the constant return to scale property of $F$, we also have:

$$
R_{t}=F_{1}\left(K_{t}, A_{t} N_{t}\right)
$$

Equation (25) follows from equation (22) and (9). We next derive aggregate investment:

$$
I_{t}=\int \frac{I_{t}^{j}}{z_{t}} d j=\int \frac{i_{t}^{j}}{z_{t}} K_{t}^{j} d j=K_{t} \int_{0}^{\xi_{t}^{*}} z_{t}^{\frac{1}{\theta}-1}\left(\psi Q_{t}\right)^{\frac{1}{\theta}} \phi(\xi) d \xi,
$$

where the second equality uses the definition of $i_{t}^{j}$, the third equality uses a law of large numbers and the optimal investment rule (23). We thus obtain (26).

We turn to the law of motion for capital. By definition,

$$
K_{t+1}=\int_{0}^{1}\left[(1-\delta)+g\left(i_{t}^{j}\right)\right] K_{t}^{j} d j .
$$

Substituting optimal investment in equation (23) and using equation (26), we obtain (27).

Equation (30) follows from substituting equations (9), (26), (25), and (A.9) into equation (24). Equation (29) follows from equations (9), (10) and (A.8). Finally, equation (28) follows from a law of large number, the market clearing condition (11), and Proposition 1. Q.E.D. 
Proof of Proposition 3: Given $\phi^{\prime} \geq 0$ and the assumptions on preferences and technology made in Section 2, we can easily check that the social planner problem is a standard concave problem. Thus, the solution exists and unique (See Stokey and Lucas (1989)). Let $\lambda_{t}$ and $\lambda_{t} Q_{t}$ be the Lagrange multipliers associated with (28) and (27), respectively. We derive the following first-order conditions:

$$
\begin{gathered}
C_{t}: U_{1}\left(C_{t}, 1-N_{t}\right)=\lambda_{t} \\
N_{t}: U_{2}\left(C_{t}, 1-N_{t}\right)=\lambda_{t} A_{t} F_{2}\left(K_{t}, A_{t} N_{t}\right) \\
I_{t}: 1=Q_{t} \psi K_{t}^{\theta} z_{t}^{1-\theta} I_{t}^{-\theta}\left[\int_{0}^{\xi_{t}^{*}} \phi(\xi) d \xi\right]^{\theta} \\
K_{t+1}: \lambda_{t} Q_{t}=E_{t} \beta \lambda_{t+1}\left[F_{1}\left(K_{t+1}, A_{t+1} N_{t+1}\right)+(1-\delta+\varsigma) Q_{t+1}-\int_{0}^{\xi_{t+1}^{*}} \xi \phi(\xi) d \xi\right] \\
+E_{t} \beta \lambda_{t+1} Q_{t+1}\left[\frac{\theta \psi}{1-\theta}\left(\frac{I_{t+1} z_{t+1}}{K_{t+1}}\right)^{1-\theta}\left(\int_{0}^{\xi_{t+1}^{*}} \phi(\xi) d \xi\right)^{\theta}\right] \\
\xi_{t}^{*}: \lambda_{t} \xi_{t}^{*} \phi\left(\xi_{t}^{*}\right) K_{t}=\lambda_{t} Q_{t} \frac{\psi \theta}{1-\theta} K_{t}\left(z_{t} I_{t} / K_{t}\right)^{1-\theta}\left[\int_{0}^{\xi_{t}^{*}} \phi(\xi) d \xi\right]^{\theta-1} \phi\left(\xi_{t}^{*}\right)
\end{gathered}
$$

Equation (A.12) gives (26). Equations (A.10) and (A.11) together give equation (29). Using equations (A.12) and (A.14), we can derive equation (25). From (25) and (26), we can derive

$$
\frac{\theta}{1-\theta} \frac{I_{t}}{K_{t}}=\int_{0}^{\xi_{t}^{*}} \xi_{t}^{*} \phi(\xi) d \xi .
$$

Using this equation and equations (A.12) and (A.13), we can derive (30). Q.E.D.

Proof of Proposition 4: We first observe that the deterministic steady-state values of $A_{t}$ and $z_{t}$ are equal to 1 . In steady state, equations (26) and (25) imply that:

$$
\begin{gathered}
\frac{I}{K}=(\psi Q)^{\frac{1}{\theta}} \int_{0}^{\xi^{*}} \phi(\xi) d \xi \\
\xi^{*}=\frac{\theta}{1-\theta}(\psi Q)^{\frac{1}{\theta}}
\end{gathered}
$$

From these two equations, we obtain:

$$
\frac{I}{K}=\xi^{*} \frac{1-\theta}{\theta} \int_{0}^{\xi^{*}} \phi(\xi) d \xi
$$


In steady state, equation (27) becomes:

$$
\delta-\varsigma=\frac{\psi}{1-\theta}(I / K)^{1-\theta}\left[\int_{0}^{\xi^{*}} \phi(\xi) d \xi\right]^{\theta} .
$$

Substituting equation (A.18) into the above equation yields equation (31). The expression on the right-hand side of this equation increases with $\xi^{*}$. Given the condition in this proposition, there is a unique interior solution $\xi^{*} \in\left[0, \xi_{\max }\right]$.

Equation (32) follows from (A.17). Equations (A.18) and (A.19) imply that:

$$
\delta-\varsigma=\frac{\psi}{1-\theta} \frac{I}{K}\left(\frac{\xi^{*}(1-\theta)}{\theta}\right)^{-\theta} .
$$

From this equation and equation (32), we obtain (33). The other equations in the proposition follow from the steady-state versions of equations (29)-(30). Q.E.D.

Proof of Corollary 1: For the power function distribution, we have $\int_{0}^{\xi} \phi(x) d x=\left[\frac{\xi}{\xi_{\max }}\right]^{\eta}$, and

$$
\frac{\int_{0}^{\xi^{*}} \xi \phi(\xi) d \xi}{\xi^{*} \int_{0}^{\xi^{*}} \phi(\xi) d \xi}=\frac{\eta}{\eta+1}
$$

We can then use equation (31) to derive equation (38). Equation (38) implies that the investment trigger $\xi^{*}$ increases with $\xi_{\max }$. It follows from equation (32) and (33) that $Q$ and $I / K$ also increase with $\xi_{\max }$.

Using equation (A.18), we can compute the steady-state value of the ratio of option value of waiting to the investment rate:

$$
\frac{\int_{0}^{\xi^{*}}\left[\xi^{*}-\xi\right] \phi(\xi) d \xi}{I / K}=\frac{\int_{0}^{\xi^{*}}\left[\xi^{*}-\xi\right] \phi(\xi) d \xi}{\frac{1-\theta}{\theta} \xi^{*} \int_{0}^{\xi^{*}} \phi(\xi) d \xi}=\frac{\theta}{1-\theta}\left[1-\frac{\int_{0}^{\xi^{*}} \xi \phi(\xi) d \xi}{\xi^{*} \int_{0}^{\xi^{*}} \phi(\xi) d \xi}\right] .
$$

Using this equation and equation (33), we derive the steady-state value of the ratio of the option value to the price of capital:

$$
\frac{\int_{0}^{\xi^{*}}\left[\xi^{*}-\xi\right] \phi(\xi) d \xi}{Q}=\frac{\int_{0}^{\xi^{*}}\left[\xi^{*}-\xi\right] \phi(\xi) d \xi}{I / K} \frac{I / K}{Q}=\theta(\delta-\varsigma)\left[1-\frac{\int_{0}^{\xi^{*}} \xi \phi(\xi) d \xi}{\xi^{*} \int_{0}^{\xi^{*}} \phi(\xi) d \xi}\right] .
$$

Substituting it into equation (36), we obtain:

$$
Q=\frac{\beta}{1-\beta(1-\delta+\varsigma)}\left\{F_{1}(K, N)+\theta(\delta-\varsigma)\left[1-\frac{\int_{0}^{\xi^{*}} \xi \phi(\xi) d \xi}{\xi^{*} \int_{0}^{\xi^{*}} \phi(\xi) d \xi}\right] Q\right\} .
$$


This equation implies that:

$$
\begin{aligned}
R & =F_{1}(K, N)=\frac{\alpha Y}{K} \\
& =Q\left\{\frac{1}{\beta}-(1-\delta+\varsigma)-\theta(\delta-\varsigma)\left[1-\frac{\int_{0}^{\xi^{*}} \xi \phi(\xi) d \xi}{\xi^{*} \int_{0}^{\xi^{*}} \phi(\xi) d \xi}\right]\right\} .
\end{aligned}
$$

Thus, by (A.21), $R / Q$ is independent of $\xi_{\max }$.

Using equations (A.21), (33) and (A.23), we derive the steady-state investment-output ratio:

$$
\frac{I}{Y}=\frac{I / K}{Y / K}=\frac{\alpha(\delta-\varsigma)(1-\theta)}{\frac{1}{\beta}-(1-\delta+\varsigma)-\frac{\theta(\delta-\varsigma)}{\eta+1}},
$$

which is independent of $\xi_{\max }$. We next compute the ratio of total fixed costs to output using equations (A.24) and (33):

$$
\begin{aligned}
\frac{K \int_{0}^{\xi^{*}} \xi \phi(\xi) d \xi}{Y} & =\int_{0}^{\xi^{*}} \xi \phi(\xi) d \xi \frac{I / Y}{I / K}=\frac{\alpha \int_{0}^{\xi^{*}} \xi \phi(\xi) d \xi}{Q\left\{\frac{1}{\beta}-(1-\delta+\varsigma)-\frac{\theta(\delta-\varsigma)}{\eta+1}\right\}} \\
& =\frac{\alpha \eta /(\eta+1)}{\frac{1}{\beta}-(1-\delta+\varsigma)-\frac{\theta(\delta-\varsigma)}{\eta+1}} \frac{\xi^{* 1+\eta-\theta} \psi \theta^{\theta}}{\xi_{\max }^{\eta}(1-\theta)^{\theta}} \\
& =\frac{\alpha \eta /(\eta+1)(\delta-\varsigma) \theta}{\frac{1}{\beta}-(1-\delta+\varsigma)-\frac{\theta(\delta-\varsigma)}{\eta+1}},
\end{aligned}
$$

which is independent of $\xi_{\max }$.

Using the resource constraint, we can compute the steady-state consumption-output ratio:

$$
\frac{C}{Y}=1-\frac{I}{Y}-\frac{K \int_{0}^{\xi^{*}} \xi \phi(\xi) d \xi}{Y} .
$$

Thus, $C / Y$ is independent of $\xi_{\max }$.

To show $N$ is independent of $\xi_{\max }$, we use the assumption on preferences and the steadystate version of equation (35) to derive:

$$
\frac{(1-\alpha) Y}{N}=C v^{\prime}(1-N) \text { or } \frac{C v^{\prime}(1-N)}{1-\gamma} .
$$

We obtain the desired result because $C / Y$ is independent of $\xi_{\max }$.

Because $Q$ increases with $\xi_{\max }$ and $R / Q$ is independent of $\xi_{\max }, R$ must increase with $\xi_{\max }$. Since $R=f^{\prime}(k)$ and $\partial R / \partial \xi_{\max }>0$, we must have $\partial k / \partial \xi_{\max }<0$, where $k=K / N$. Because $N$ is independent of $\xi_{\max }$, we obtain $\partial K / \partial \xi_{\max }<0$. Since $w=f(k)-f^{\prime}(k) k$, so we have $\partial w / \partial k>0$ and $\frac{\partial w}{\partial \xi_{\max }}=\frac{\partial w}{\partial k} \frac{\partial k}{\partial \xi_{\max }}<0$. Since $Y=F(K, N)$, we have $\partial Y / \partial \xi_{\max }<0$. Since $C / Y$ and $I / Y$ are independent of $\xi_{\max }$, we also have $\partial C / \partial \xi_{\max }<0$ and $\partial I / \partial \xi_{\max }<0$. Q.E.D. 
Proof of Proposition 5: We focus on the utility function $U(C, 1-N)=\frac{C^{1-\gamma}}{1-\gamma} v(1-N)$, where $\gamma>0, \neq 1$. The proof for the other utility function in the proposition is similar. We then have $\Lambda_{t}=C_{t}^{-\gamma} v\left(1-N_{t}\right)$, and

$$
\frac{U_{2}\left(C_{t}, 1-N_{t}\right)}{U_{1}\left(C_{t}, 1-N_{t}\right)}=\frac{1}{\gamma-1} \frac{C_{t} v^{\prime}\left(1-N_{t}\right)}{v\left(1-N_{t}\right)} .
$$

Using Proposition 2 and the assumptions, we can characterize the equilibrium dynamics by the following system of difference equations:

$$
\begin{gathered}
I_{t}=\left(\psi Q_{t}\right)^{\frac{1}{\theta}} z_{t}^{\frac{1-\theta}{\theta}} K_{t}\left(\frac{\xi_{t}^{*}}{\xi_{\max }}\right)^{\eta} \\
K_{t+1}=(1-\delta+\varsigma) K_{t}+\frac{\psi}{1-\theta} K_{t}\left(z_{t} I_{t} / K_{t}\right)^{1-\theta}\left(\frac{\xi_{t}^{*}}{\xi_{\max }}\right)^{\theta \eta}, \\
\xi_{t}^{*}=\frac{\theta}{1-\theta} z_{t}^{\frac{1-\theta}{\theta}}\left(\psi Q_{t}\right)^{\frac{1}{\theta}}, \\
\frac{1}{\gamma-1} \frac{C_{t} v^{\prime}\left(1-N_{t}\right)}{v\left(1-N_{t}\right)}=\frac{(1-\alpha) Y_{t}}{N_{t}}, \\
Q_{t}=E_{t}\left\{\frac{\beta C_{t+1}^{-\gamma} v\left(1-N_{t+1}\right)}{C_{t}^{-\gamma} v\left(1-N_{t}\right)}\left[\frac{\alpha Y_{t+1}}{K_{t+1}}+(1-\delta+\varsigma) Q_{t+1}+\frac{1}{\eta+1} \frac{\left(\xi_{t}^{*}\right)^{\eta+1}}{\left(\xi_{\max }\right)^{\eta}}\right]\right\} .
\end{gathered}
$$

Using the steady-state equations from Corollary 1 and the definition of normalization, $X_{t}=X \tilde{X}_{t}$ for any variable $X_{t}$, we can rewrite the above system of difference equations as follows:

$$
\begin{gathered}
\tilde{I}_{t}=\tilde{Q}_{t}^{\frac{1}{\theta}} \tilde{z}_{t}^{\frac{1-\theta}{\theta}} \tilde{K}_{t}\left(\tilde{\xi}_{t}^{*}\right)^{\eta} \\
\tilde{K}_{t+1}=(1-\delta+\varsigma) \tilde{K}_{t}+\frac{\psi[(\delta-\varsigma)(1-\theta)]^{1-\theta}}{1-\theta} \tilde{K}_{t}\left(\tilde{z}_{t} \tilde{I}_{t} / \tilde{K}_{t}\right)^{1-\theta}\left(\tilde{\xi}_{t}^{*}\right)^{\theta \eta}, \\
\tilde{\xi}_{t}^{*}=\tilde{z}_{t}^{\frac{1-\theta}{\theta}} \tilde{Q}_{t}^{\frac{1}{\theta}} \\
\frac{1}{\gamma-1} \frac{\tilde{C}_{t} v^{\prime}\left(1-N \tilde{N}_{t}\right)}{v\left(1-N \tilde{N}_{t}\right)}=\frac{Y}{C} \frac{(1-\alpha) \tilde{Y}_{t}}{N \tilde{N}_{t}}, \\
\tilde{Y}_{t}=\tilde{K}_{t}^{\alpha}\left(\tilde{A}_{t} \tilde{N}_{t}\right)^{1-\alpha}=\frac{I}{Y} \tilde{I}_{t}+\frac{C}{Y} \tilde{C}_{t}+\left(1-\frac{I}{Y}-\frac{C}{Y}\right) \tilde{K}_{t}\left(\tilde{\xi}_{t}^{*}\right)^{\eta+1}, \\
\tilde{Q}_{t}=E_{t}\left\{\frac { \beta \tilde { C } _ { t + 1 } ^ { - \gamma } v ( 1 - N \tilde { N } _ { t + 1 } ) } { \tilde { C } _ { t } ^ { - \gamma } v ( 1 - N \tilde { N } _ { t } ) } \left[\frac{R}{Q} \frac{\tilde{Y}_{t+1}}{\tilde{K}_{t+1}}+(1-\delta+\varsigma) \tilde{Q}_{t+1}\right.\right. \\
\left.\left.\frac{\int_{0}^{\xi^{*}}\left(\xi^{*}-\xi\right) \phi(\xi) d \xi}{Q}\left(\tilde{\xi}_{t}^{*}\right)^{\eta+1}\right]\right\}
\end{gathered}
$$


Note that equation (A.22) implies:

$$
\frac{\int_{0}^{\xi^{*}}\left(\xi^{*}-\xi\right) \phi(\xi) d \xi}{Q}=\frac{1}{\beta}-(1-\delta+\varsigma)-\frac{R}{Q} .
$$

The dynamics of the above system of nonlinear difference equations are fully determined by the steady-state ratios $R / Q$ and $C / Y, I / Y$ and the steady-state value $N$, structural parameters $\{\alpha, \beta, \gamma, \delta, \psi, \varsigma, \theta, \eta\}$, the function $v(1-N)$, and the process of exogenous technology shocks $\tilde{A}_{t}$ and $\tilde{z}_{t}$. By Corollary $1, R / Q, C / Y, I / Y$ and the steady-state value $N$ are independent of the nonconvex adjustment costs parameter $\xi_{\max }$. Thus, we obtain the desired result. Q.E.D.

Proof of Proposition 6: We log-linearize the nonlinear dynamic system in Proposition 2 and obtain equations (51), (49), (48), (50), (52) and

$$
\begin{aligned}
\hat{Q}_{t}+u_{C, C} \hat{C}_{t}-u_{C, N} \hat{N}_{t}= & E_{t}\left(u_{C, C} \hat{C}_{t+1}-u_{C, N} \hat{N}_{t+1}\right)+\beta(1-\delta+\varsigma) E_{t} \hat{Q}_{t+1} \\
& +\frac{\beta F_{1}}{Q} E_{t}\left[f_{K K} \hat{K}_{t+1}+f_{K N}\left(\hat{A}_{t+1}+\hat{N}_{t+1}\right)\right] \\
& +\beta \theta(\delta-\varsigma) E_{t}\left(\hat{I}_{t+1}-\hat{K}_{t+1}\right)-\frac{\beta\left(\xi^{*}\right)^{2} \phi\left(\xi^{*}\right)}{Q} E_{t} \hat{\xi}_{t+1}^{*},
\end{aligned}
$$

where we have used (A.15) in (30) to derive the above equation. Following King, Plosser and Rebelo (2002), we denote the elasticities of marginal utility to its arguments by $u_{N, C}=$ $\frac{C U_{21}(C, 1-N)}{U_{2}(C, 1-N)}, u_{N, N}=\frac{N U_{22}(C, 1-N)}{U_{2}(C, 1-N)}, u_{C, C}=\frac{C U_{11}(C, 1-N)}{U_{1}(C, 1-N)}, u_{C, N}=\frac{N U_{12}\left(C_{t}, 1-N\right)}{U_{1}(C, 1-N)}$. We then loglinearize equation (29) to obtain equation (55). We log-linearize the equation $U_{1}\left(C_{t}, 1-N_{t}\right)=$ $\beta E_{t}\left[U\left(C_{t+1}, 1-N_{t+1}\right) r_{t+1}\right]$ to obtain (54).

We now use equation (49) to derive

$$
\beta \theta(\delta-\varsigma) E_{t}\left(\hat{I}_{t+1}-\hat{K}_{t+1}\right)=\beta(\delta-\varsigma) E_{t}\left[\hat{Q}_{t+1}+(1-\theta) \hat{z}_{t+1}+\frac{\theta \xi^{*} \phi\left(\xi^{*}\right)}{\int_{0}^{\xi^{*}} \phi(\xi) d \xi} \hat{\xi}_{t+1}^{*}\right] .
$$

By equations (A.18) and (33), we have:

$$
\frac{\theta}{1-\theta} \frac{I}{K}=\xi^{*} \int_{0}^{\xi^{*}} \phi(\xi) d \theta=(\delta-\varsigma) \theta Q
$$

Thus,

$$
\beta(\delta-\varsigma) \frac{\theta \xi^{*} \phi\left(\xi^{*}\right)}{\int_{0}^{\xi^{*}} \phi(\xi) d \xi}=\beta(\delta-\varsigma) \frac{\theta\left(\xi^{*}\right)^{2} \phi\left(\xi^{*}\right)}{(\delta-\varsigma) \theta Q}=\beta \frac{\left(\xi^{*}\right)^{2} \phi\left(\xi^{*}\right)}{Q} .
$$

Using this equation and plugging equation (A.38) into (A.37), we obtain:

$$
\begin{aligned}
& \hat{Q}_{t}+u_{C, C} \hat{C}_{t}-u_{C, N} \hat{N}_{t} \\
= & E_{t}\left(u_{C, C} \hat{C}_{t+1}-u_{C, N} \hat{N}_{t+1}\right)+\beta E_{t} \hat{Q}_{t+1}+\beta(\delta-\varsigma)(1-\theta) E_{t} \hat{z}_{t+1} \\
& +\frac{\beta F_{1}}{Q} E_{t}\left[\frac{K F_{11}(K, N)}{F_{1}(K, N)} \hat{K}_{t+1}+\frac{N F_{12}(K, N)}{F_{1}(K, N)}\left(\hat{A}_{t+1}+\hat{N}_{t+1}\right)\right] .
\end{aligned}
$$


Because $F$ is linearly homogenous, we have

$$
N F_{22}+K F_{21}=0, K F_{11}+N F_{12}=0
$$

We can then derive:

$$
\begin{gathered}
\frac{K F_{11}(K, N)}{F_{1}(K, N)} \hat{K}_{t+1}+\frac{N F_{12}(K, N)}{F_{1}(K, N)}\left(\hat{A}_{t+1}+\hat{N}_{t+1}\right)=\frac{K F_{11}(K, N)}{F_{1}(K, N)}\left(\hat{K}_{t+1}-\hat{A}_{t+1}-\hat{N}_{t+1}\right), \\
\hat{w}_{t+1}=\frac{K F_{21}}{F_{2}} \hat{K}_{t+1}+\frac{N F_{22}}{F_{2}} \hat{N}_{t+1}+\left(1+\frac{N F_{22}}{F_{2}}\right) \hat{A}_{t+1} \\
=\hat{A}_{t+1}+\frac{K F_{21}}{F_{2}}\left(\hat{K}_{t+1}-\hat{A}_{t+1}-\hat{N}_{t+1}\right) .
\end{gathered}
$$

Using the above two equations, we can derive equation (53) from equation (A.39). Q.E.D. 


\section{References}

Abel, Andrew B. and Janice C. Eberly, 1994, "A Unified Model of Investment under Uncertainty," American Economic Review 84, 1369-1384.

Abel, Andrew B. and Janice C. Eberly, 1996, "Optimal investment with costly irreversibility," Review of Economic Studies 63, 581-593.

Abel, Andrew B. and Janice C. Eberly, 1998, "The Mix and Scale of Factors with Irreversibility and Fixed Costs of Investment," in Bennett McCallum and Charles Plosser (eds.) Carnegie-Rochester Conference Series on Public Policy 48, 101-135.

Aruoba, S. Boragn, Jesus Fernandez-Villarerde, and Juan F. Rubio-Ramirez, 2006, "Comparing Solution Methods for Dynamic Economic Models," Journal of Economic Dynamics and Control 30, 2477-2508.

Bachmann, Ruediger; Caballero, Ricardo, and Engel, Eduardo. 2008. "Aggregate Implications of Lumpy Investment: New Evidence and a DSGE Model." NBER working paper No. 12336.

Baxter, Marianne and Mario J. Crucini, 1993, "Explaining Saving-Investment Correlations," American Economic Review 83, 416-436.

Caballero, Ricardo and Engel, Eduardo. 1999. "Explaining Investment Dynamics in U.S. Manufacturing: A Generalized (S,s) Approach." Econometrica, 67(4), pp. 783-826.

Caballero, Ricardo; Engel, Eduardo and Haltiwanger, John. 1995. "Plant-Level Adjustment and Aggregate Investment Dynamics." Brookings Papers on Economic Activity, Vol. 1995, No. 2, pp. 1-54.

Caballero, Ricardo, and Leahy, John V. 1996. "Fixed Costs: The Demise of Marginal q." NBER working paper No. 5508.

Cooper, Russell and Haltiwanger, John. 2006. "On the Nature of Capital Adjustment Costs." Review of Economic Studies, 73, pp. 611-634.

Cooper, Russell, Haltiwanger, John and Power, Laura. 1999. "Machine Replacement and the Business Cycle: Lumps and Bumps.” American Economic Review 89, 921-946. 
den Haan, Wouter J., 2010a, "Comparison of Solutions to the Incomplete Markets Model with Aggregate Uncertainty," Journal of Economic Dynamics and Control 34, 4-27.

den Haan, Wouter J., 2010b, "Assessing the Accuracy of the Aggregate Law of Motion in Models with Heterogeneous Agents," Journal of Economic Dynamics and Control 34, 79-99.

Doms, Mark and Dunne, Timothy. 1998. "Capital Adjustment Patterns in Manufacturing Plants." Review of Economic Dynamics 1, 409-429.

Dotsey, M.; King, R. and Wolman, A. 1999. "State Dependent Pricing and the General Equilibrium Dynamics of Money and Output," Quarterly Journal of Economics, 104, 655-690.

Fisher, Jonas D.M. 2006. "The Dynamic Effects of Neutral and Investment-Specific Technology Shocks." Journal of Political Economy 114, 413-452.

Gourio, Francois and Kashyap, Anil. 2007. "Investment Spikes: New Facts and a General Equilibrium Exploration." Journal of Monetary Economics, 54: Supplement 1, pp. 1-22.

Greenwood, J., Hercowitz, Z., and P. Krusell, 2000, "The role of investment-specific technological change in the business cycle," European Economic Review 44, 91-115.

Hayashi, Fumio. 1982. "Tobin's Marginal q and Average q: A Neoclassical Interpretation." Econometrica 50, 213-224.

Heathcote, Jonathan, Kjetil Storesletten, and Giovanni L. Violante, 2009, "Quantitative Macroeconomics with Heterogeneous Households," Annual Review of Economics 1, 319354.

House, Christopher L., 2008, "Fixed Costs and Long-Lived Investments," working paper, University of Michigan.

Jermann, Urban J., 1998, "Asset Pricing in Production Economies," Journal of Monetary Economics 41, 257-275.

Khan, Aubhik and Thomas, Julia. 2003. "Nonconvex Factor Adjustments in Equilibrium Business Cycle Models: Do Nonlinearities Matter?" Journal of Monetary Economics 50, 331-360. 
Khan, Aubhik and Thomas, Julia. 2008. "Idiosyncratic Shocks and the Role of Nonconvexities in Plant and Aggregate Investment Dynamics." Econometrica, 76(2), pp. 395-436.

King, Robert G., Charles I. Plosser, and Sergio T. Rebelo, 2002, "Production, Growth and Business Cycles: Technical Appendix," Computational Economics 20, 87-116.

Krusell, P., and Smith, A. 1998. "Income and Wealth Heterogeneity in the Macroeconomy." Journal of Political Economy 106, 867-898.

Miao, Jianjun, 2006, "Competitive Equilibria of Economies with a Continuum of Consumers and Aggregate Shocks," Journal of Economic Theory 128, 274-298.

Miao, Jianjun, 2008, "Corporate Tax Policy and Long-Run Capital Formation: The Role of Irreversibility and Fixed Costs," working paper, Boston University.

Prescott, Edward C., 1986, "Theory Ahead of Business Cycle Measurement," Federal Reserve Bank of Minneapolis Quarterly Review 10, 9-22.

Stock, James H., Mark W. Watson, 1999, Business cycle fluctuations in U.S. macroeconomic time series. In: Woodford, M., Taylor, J. (Eds.), Handbook of Macroeconomics IA. Elsevier Science, Amsterdam, pp. 3-64.

Stokey, Nancy and Robert E. Lucas with Edward C. Prescott, 1989, Recursive Methods in Economic Dynamics, Harvard University Press.

Thomas, Julia. 2002. "Is Lumpy Investment Relevant for the Business Cycle?" Journal of Political Economy 110, 508-534.

Uzawa, Hirofumi, 1969, "Time Preference and the Penrose Effect in a Two-Class Model of Economic Growth," Journal of Political Economy 77, 628-52.

Veracierto, Marcelo. L. 2002. "Plant-Level Irreversible Investment and Equilibrium Business Cycles." American Economic Review 92, 181-197.

Wang, Pengfei and Yi Wen, 2009, "Financial Deveolpment and Economic Volatility: A Unified Explanation," working paper, Hong Kong University of Science and Technology. 

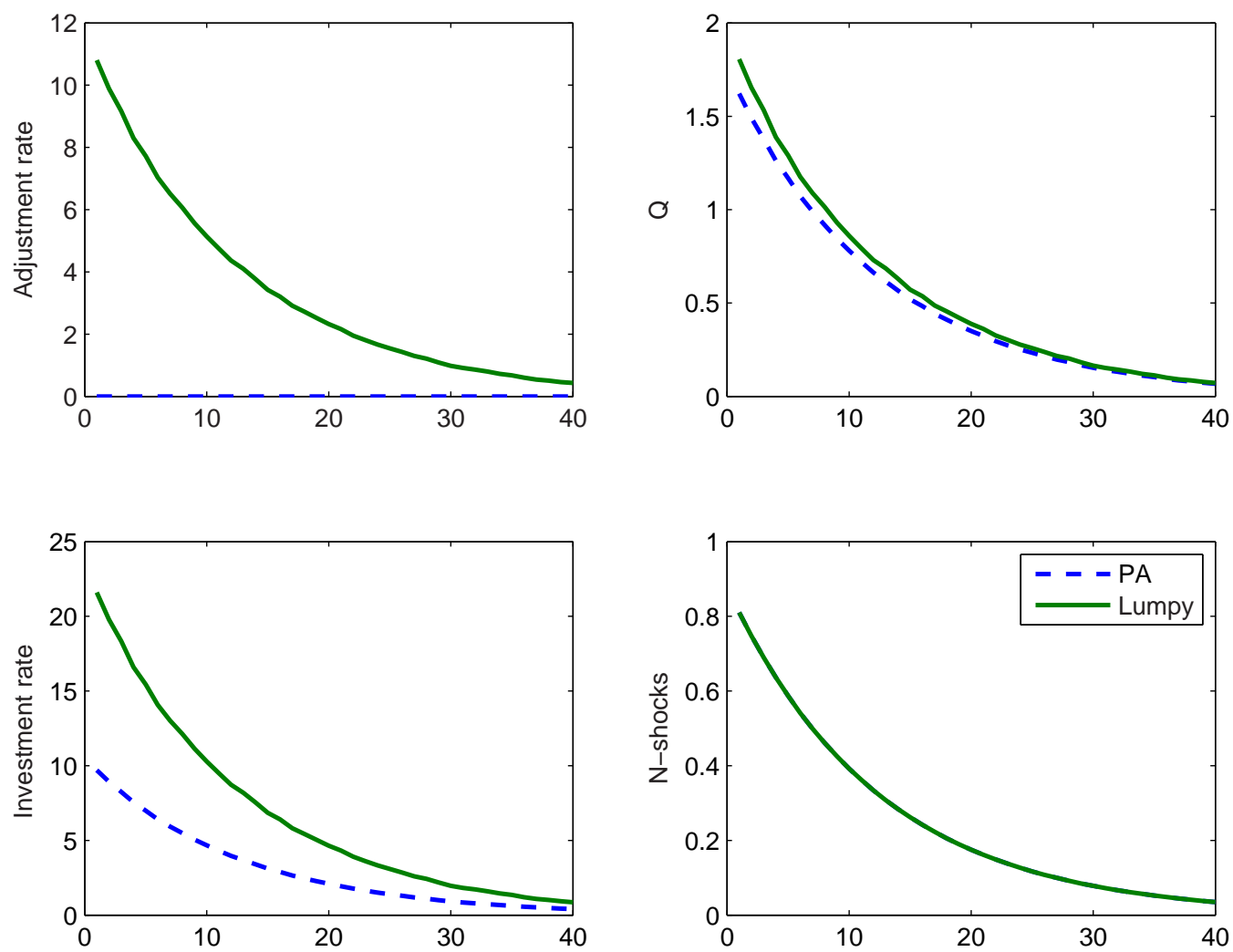

Figure 1: Impulse responses to an $\mathbf{N}$-shock in partial equilibrium. This figure plots impulse responses (measured in percentage) to a standard deviation positive shock to the laboraugmenting technology in partial equilibrium. PA: partial adjustment model. Lumpy: lumpy investment model. 

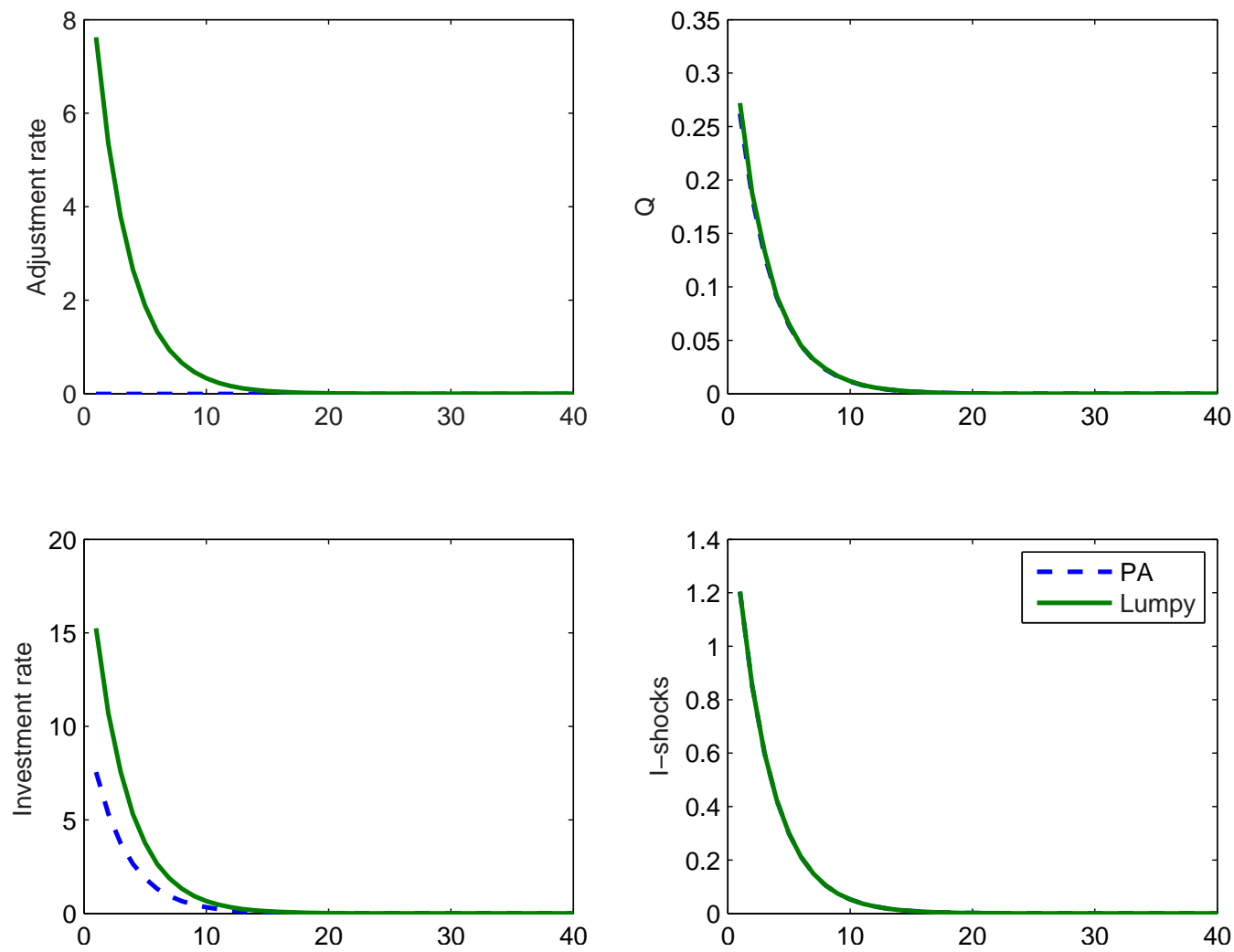

Figure 2: Impulse responses to an I-shock in partial equilibrium. This figure plots impulse responses (measured in percentage) to a standard deviation positive shock to the investment-specific technology in partial equilibrium. PA: partial adjustment model. Lumpy: lumpy investment model. 

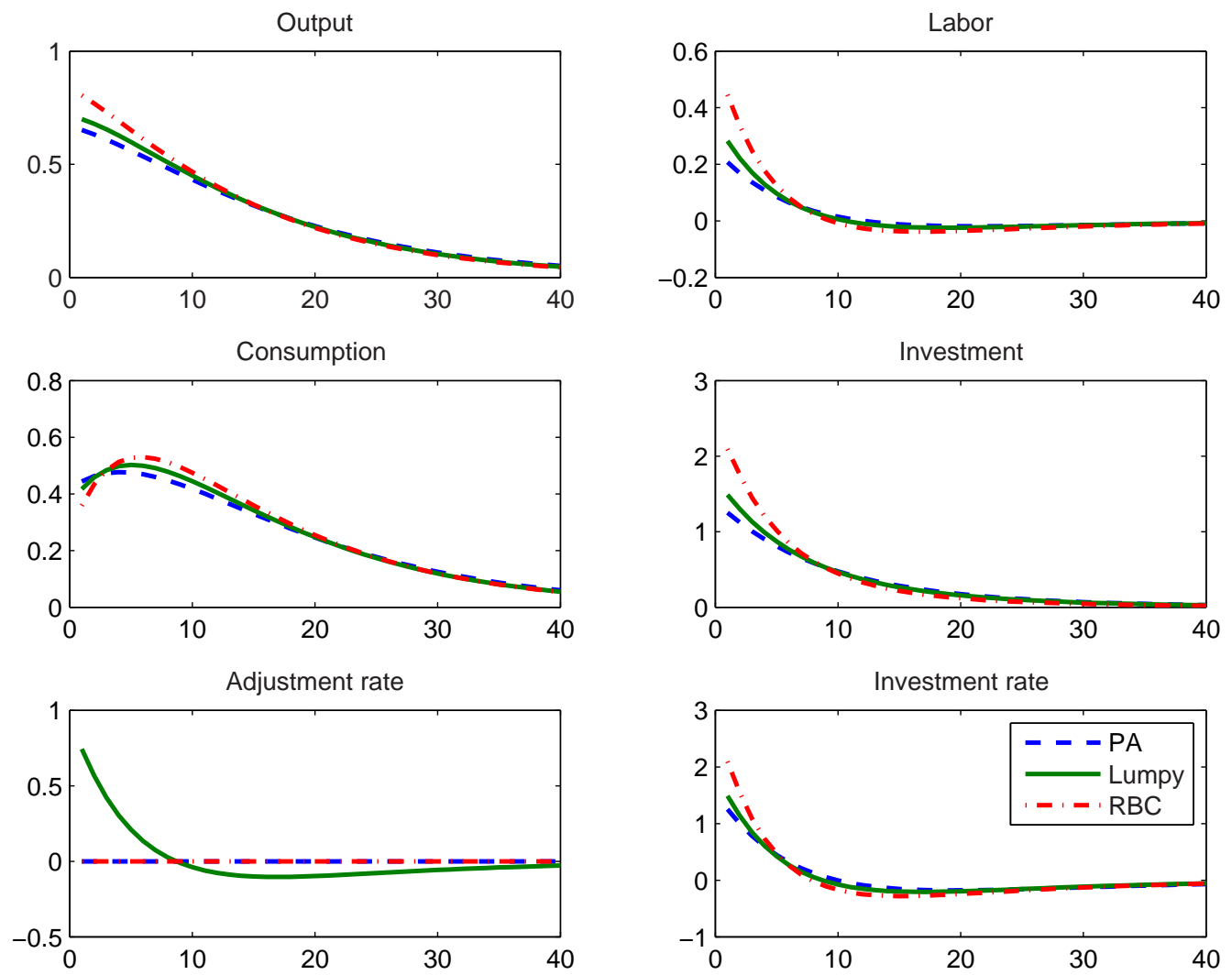

Figure 3: Impulse responses to an $\mathrm{N}$-shock in general equilibrium. This figure plots impulse responses (measured in percentage) of quantities to a standard deviation positive shock to the labor-augmenting technology in general equilibrium. PA: partial adjustment model. Lumpy: lumpy investment model. RBC: frictionless RBC model. 

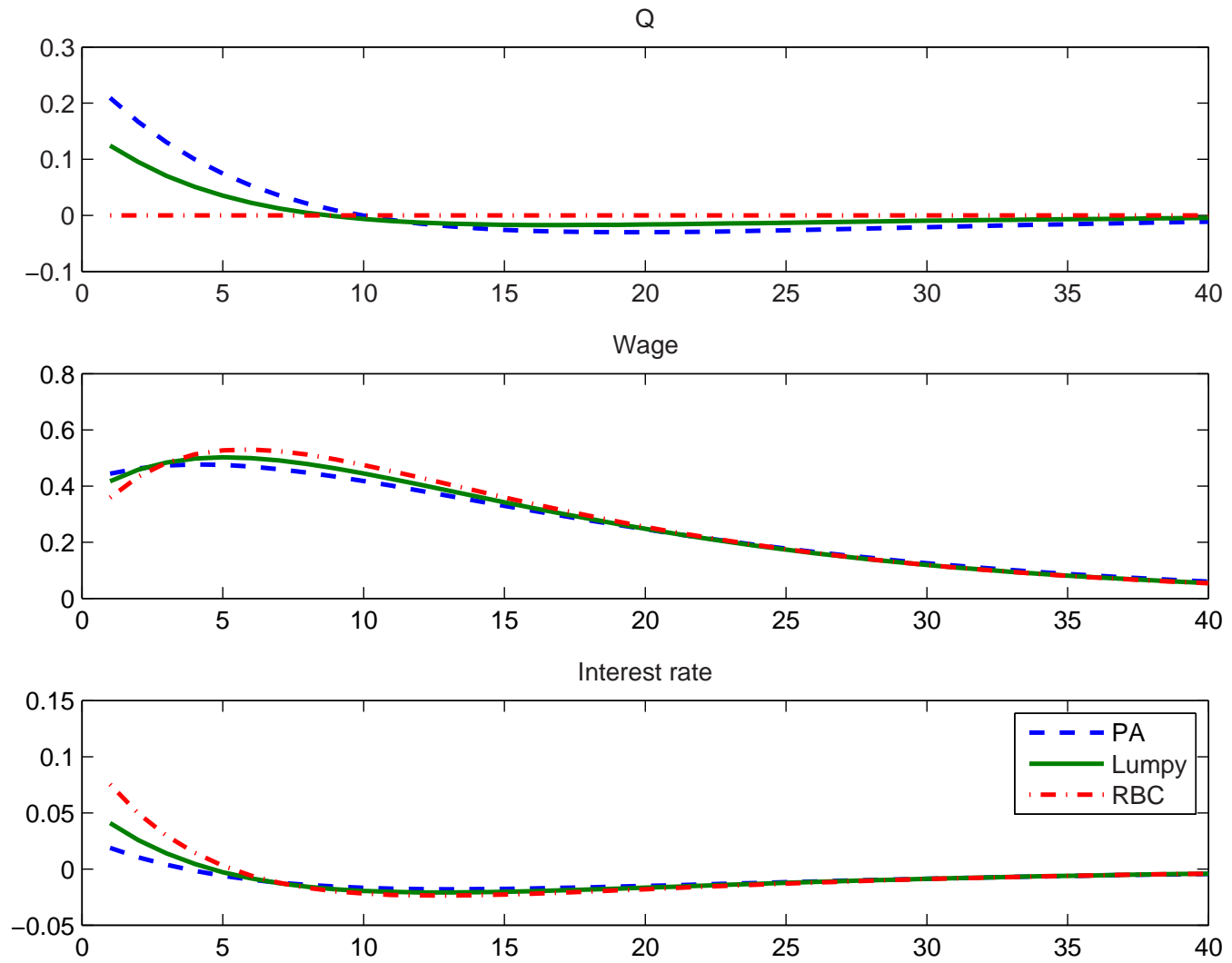

Figure 4: Impulse responses to an $\mathrm{N}$-shock in general equilibrium. This figure plots impulse responses (measured in percentage) of prices to a standard deviation positive shock to the labor-augmenting technology in general equilibrium. PA: partial adjustment model. Lumpy: lumpy investment model. RBC: frictionless RBC model. 

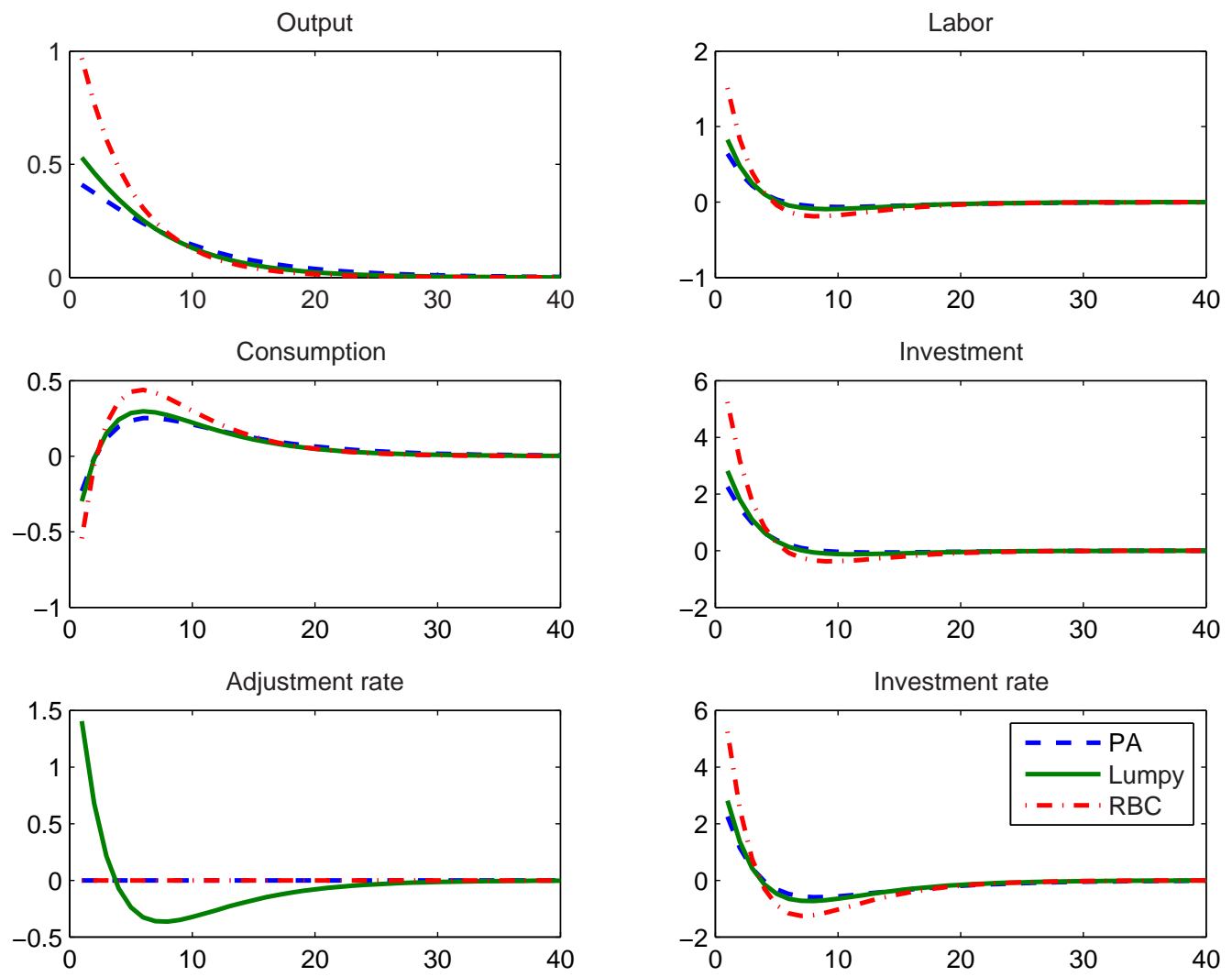

Figure 5: Impulse responses of an I-shock in general equilibrium. This figure plots impulse responses (measured in percentage) of quantities to a standard deviation positive shock to the investment-specific technology in general equilibrium. PA: partial adjustment model. Lumpy: lumpy investment model. RBC: frictionless RBC model. 

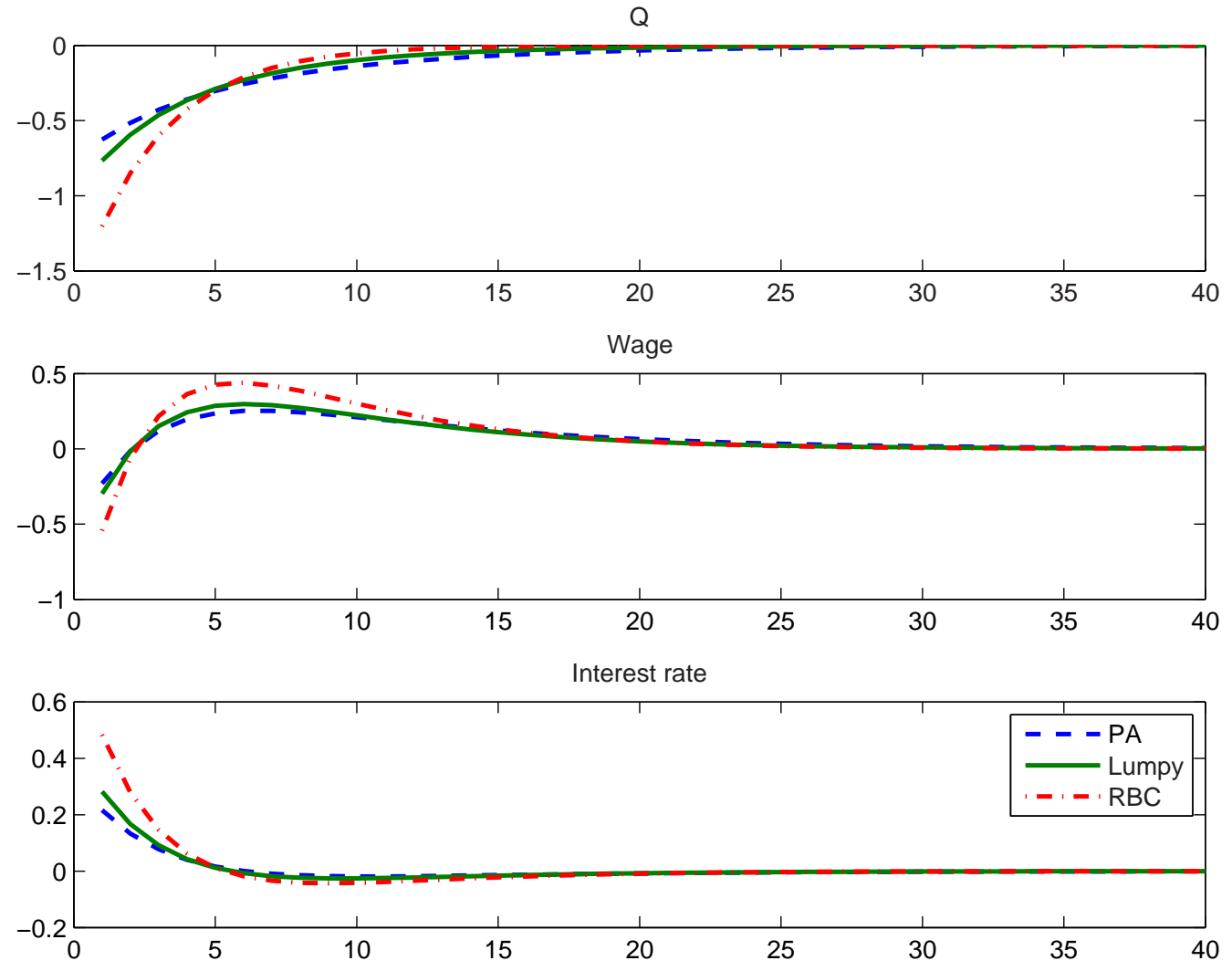

Figure 6: Impulse responses of an I-shock in general equilibrium. This figure plots impulse responses (measured in percentage) of prices to a standard deviation positive shock to the investment-specific technology in general equilibrium. PA: partial adjustment model. Lumpy: lumpy investment model. RBC: frictionless RBC model. 